\title{
Cue-Sampling and Goal-Approach Correlates of Hippocampal Unit Activity in Rats Performing an Odor-Discrimination Task
}

\author{
H. Elchenbaum, M. Kuperstein, A. Fagan, and J. Nagode \\ Department of Biological Sciences, Wellesley College, Wellesley, Massachusetts 02181
}

\begin{abstract}
Several techniques previously used to describe behavioral correlates of hippocampal unit and slow-wave activity are combined in a single odor-discrimination paradigm. Rats repetitively performed a sequence of behaviors during each trial: approach to a stimulus-sampling port, investigatory sniffing of the odor cue, orientation and approach toward a separate reward location, and water reward consumption. In a series of post hoc analyses, spike activity was timelocked to variations of each task event to uncover behavioral and physiological parameters that best synchronized unit firing. Three major categories of cells were identified: (1) "Cue-sampling" cells fired after onset of odor-cue sampling. Response magnitude was related to cue valence on both the current and past trials. (2) "Goal-approach" cells fired prior to arrival at either the odor-sampling port or reward cup. A number of sampling and approach cells also had place correlates. However, detailed analyses indicated that specific behaviors associated with increased firing reliably occurred at the same place. Unit activity was at least as well described by behavioral as spatial parameters. (3) "Theta" cells fired at high rates in strict relation to the ongoing limbic theta rhythm.

This categorization suggests a functional organization of the hippocampus in which different cell types play complementary roles. Cue-sampling cells activated by discriminative stimuli during attentive fixations may be involved in comparing relative cue valence. Goal-approach cells may be involved in orientation movements for successive cuesampling periods. Theta cells may provide synchronization of sensory acquisition during sampling, as well as in orientation movements during approach.
\end{abstract}

Despite extensive investigations of the hippocampus, we have only a vague understanding of its global functional role and little insight into its fundamental organization for information coding. The hippocampus is many synapses away from both receptor and effector neurons, so it is perhaps not surprising that progress in clarifying the functional correlates of hippocampal neurons has lagged behind that of sensory and motor neurons,

\footnotetext{
Received Apr. 7, 1986; revised Sept. 8, 1986; accepted Sept. 13, 1986.

Supported by HHS NS18744, NSF BNS85-07677, and ONR N00014-83-K0037. We thank Andrea Robertson for help in data collection and analysis, Neal Cohen, John O'Keefe, James Ranck, and Jon Winson for their comments on a preliminary version of the manuscript, and Sidney Wiener for his comments on the final version. Our conclusions have benefitted by discussions of the Memory Working Group (N. Cohen, P.I.) supported by the Sloan Foundation.

Correspondence should be addressed to Howard Eichenbaum at the above address.

Copyright (c) 1987 Society for Neuroscience $0270-6474 / 87 / 030716-17 \$ 02.00 / 0$
}

whose activities are synchronized with observable events. Indeed, one might expect the hippocampus to be active in "cognitive" computations that lack obvious correlation with discrete events.

Several studies have identified reliable behavioral correlates of hippocampal unit activity. The dilemma is that the qualities of these correlates vary as much as the behavioral paradigms used to reveal them. Many of the descriptions fail to overlap, and some are contradictory. A number of studies have focused on hippocampal unit correlates of learning (Segal and Olds, 1972, 1973; Segal et al., 1972; Deadwyler et al., 1979; Thompson et al., 1980; West et al., 1981; Berger et al., 1983). These studies have consistently described increased unit activity associated with particular stimulus-response-reinforcement contingencies. Unfortunately, their conclusions differ about the temporal qualities and experimental contingencies of unit firing. For example, Segal, Deadwyler, and colleagues describe increased firing of single units 30-100 msec after onset of conditioned stimuli in an instrumental tone-discrimination task. In contrast, Berger and colleagues describe equally striking increases in multiunit activity not synchronized to the stimulus but preceding and modeling the conditioned motor response in a classically conditioned tone discrimination.

Other investigators have described different behavioral correlates of hippocampal unit activity in nonlearning paradigms. In his pioneering study of single neurons in freely behaving rats, Ranck (1973) identified several functional types of neurons, including a number of types firing selectively in relation to specific appetitive movements. Rose (1983) also described movement-related behavioral correlates of hippocampal neurons in an unstructured behavioral situation. In contrast, O'Keefe and several other investigators claim that most hippocampal pyramidal cells encode "place," in that they fire in relation to the location of the animal in its environment, relatively independent of ongoing behavior and unrelated to any particular stimulus (O'Keefe, 1976, 1979, 1983; Hill, 1978; Olton et al., 1978; O'Keefe and Conway, 1980; Best and Ranck, 1982; Kubie and Ranck, 1983; Muller et al., 1983; Muller and Kubie, 1984; Jones-Leonard et al., 1985). This vicw has been detailed in a theory of the hippocampus as a cognitive map (O'Keefe and Nadel, 1978).

The differences among the conclusions of these studies have led some to compare the activity of the same hippocampal units in animals successively exposed to a conditioning task and to a separate open-field environment suitable for examining spatial qualities of unit activity. For example, in a preliminary report, Best and Thompson (1984) demonstrated that place units also increase firing following presentation of a tone stimulus in a conditioned emotional-response task. On the other hand, Chris- 
tian and Deadwyler (1986) conclude from the results of a similar study that place units do not respond to conditioned stimuli. Rather, these investigators argue that a class of non-place neurons (theta cells) are those units that demonstrate responses to conditioning stimuli. Clearly, this approach has not led to a compelling single descriptor that predicts unit activity changes across all situations.

Our approach was to combine several of the above-described parameters into a single task and to compare directly the extent to which unit activity could be correlated with different physiological, behavioral, and spatial factors. The behavioral paradigm was an instrumental odor discrimination, previously shown by us to involve hippocampal function (Macrides et al., 1982; Eichenbaum et al., 1986). Using a controlled odor-delivery system and direct monitors of sniffing and locomotory activity, the paradigm allowed precise stimulus control and response definition, as in the conditioning paradigms. The task involved a range of behavioral events (e.g., stimulus sampling, reward consumption) performed throughout a large spatial environment, permitting examination of movement and place correlates of cell firing. Moreover, the task involved multiple repetitions of the behavioral sequence, allowing tests for the reliability of unit firing related to specific events. We exploited the repetitive nature of these events, time-locking and averaging unit activity relative to the onset of each event. We directly compared the extent to which independently defincd task cvents could account for variations in unit activity over the same general time period. Events and physiological conditions that best synchronized unit activity were combined to classify the behavioral correlates of each cell.

\section{Materials and Methods}

Subjects. Experiments were performed on 350-400 gm male Long Evans rats obtained from Charles River Breeding Laboratories, Inc. (Wilmington, MA). They were deprived of water for $48 \mathrm{hr}$ before initial training and given water only during training and for 30 min after training sessions. All subjects were trained preoperatively in the odordiscrimination task, then given water ad libitum for at least $48 \mathrm{hr}$ before surgery. The deprivation schedule and training resumed 2-4 d after electrode implantation.

Behavioral apparatus. Our apparatus and procedures were adapted from those used earlier to study the effects of fornix lesions and the role of the limbic theta rhythm in olfactory discrimination learning (Macrides et al., 1982; Eichenhaum et al., 1986). The behavioral chamber was a $73 \times 84 \mathrm{~cm}$ metallic arena with walls slanted at $20^{\circ}$ to eliminate recording artifacts otherwise caused when the rat bumps its head stage against the walls (Fig. 1A). A conical stimulus sampling port was located $10 \mathrm{~cm}$ above the floor in the center of the short wall of the chamber. Odor stimuli were generated by a flow-dilution glass and Teflon olfactometer. Pressurized air was dehydrated with calcium chloride, deodorized with activated charcoal, and then rehydrated with deionized water. Clean air was delivered continuously at $1000 \mathrm{ml} / \mathrm{min}$ to a solenoid valve just outside of the port. Using other solenoid valves, an odorsaturated airstream at $40 \mathrm{ml} / \mathrm{min}$ could be chosen from among 8 odor channels and added to the clean airstream, resulting in odor concentrations at $4 \%$ saturation. Presentation of odor stimuli to the animal was controlled precisely by manipulations of the odor and port solenoid valves. During the initial $8 \mathrm{sec}$ of an intertrial interval (ITI), only clean air passed to the port solenoid valve and was exhausted without going into the port. During the last $2 \mathrm{sec}$ of the ITI, the odor stream was added, but the diluted stream was still exhausted at the port solenoid. Only when the rat performed a nose poke after offset of the ITI was the port solenoid switched to allow odor flow into the port. Paired odors were selected for their similar qualities. The odor pairs were $\mathrm{C}-14$ and $\mathrm{C}-16$ alkenes, eugenol and guiacol, geraniol and phenethyl alcohol, and methyl-and dimethyl-anthranilate. They were diluted to intensities that human observers judged as weak and similar. A reward delivery cup was located initially on the floor beneath the stimulus port and was mounted on a motorized track to allow movement of the cup towards the opposite end of the chamber.

Behavioral training. Initial training without odor stimuli proceeded in gradual stages under computer control. The rat was shaped to hold its nose in the port for $2 \mathrm{sec}$ to obtain $0.05 \mathrm{ml}$ water delivered into a reward cup located just below the port. At the same time, the cup was slowly moved to the opposite wall of the chamber. Then the ITI, identified by a continuous $400 \mathrm{~Hz}$ tone, was gradually increased to $10 \mathrm{sec}$ and its termination signaled by offset of the tone. Nose pokes performed during the last $2 \mathrm{sec}$ of the ITI were punished by prolongation of the ITI for an additional $2 \mathrm{sec}$. When rats learned to await the trial initiation signal and consistently completed the nose poke, odor-discrimination training began. The valences of "positive" $(\mathbf{S}+)$ and negative $(\mathbf{S}-)$ odors were arbitrarily assigned. Full $2 \mathrm{sec}$ nose pokes $(\mathrm{R}+)$ during presentation of $\mathbf{S}+$ were rewarded, but no reward was given after presentation of $\mathrm{S}-$, regardless of response. Rats continued to consistently perform the $\mathrm{R}+$ during $\mathrm{S}+$ and gradually learned to withdraw the nose in less than $2 \sec \left(R_{-}-\right)$during $S_{-}-$. In early experiments, a series of 4 pairwise discriminations was given, then all 8 odors were presented concurrently with the same reward contingencies. The order of $S+$ and $S-$ presentations was a randomized sequence with the following conditions: In every 48 trial block there were equal numbers of of S+ and S- stimuli, and 1 stimulus valence was equally likely to follow itself as the other stimulus valence.

Recording. Each subject was prepared with a combination of recording devices: (1) for recording unit activity, in early experiments, a fixed multichannel microelectrode made of a bundle of $25 \mu \mathrm{m}$ Teflon-coated Pt-Ir wires (Eichenbaum et al., 1977) implanted in the hilus of the dentate gyrus; or, in later experiments, a movable version of this electrode (Kubie, 1984) with $25 \mu$ m epoxy-coated stainless steel wires driven through hippocampal area CA1; (2) for recording hippocampal slowwave activity, a twisted pair of Teflon-coated, $125 \mu \mathrm{m}$ stainless steel macroelectrodes implanted with the noninverting (positive) electrode above and the inverting (negative) electrode below the CAl pyramidal cell layer contralateral to the microelectrode; (3) for monitoring sniffing, a stainless steel cannula implanted in the nasal cavity to allow insertion of a thermocouple generating voltage oscillations that correlated with nasal air temperature variations during the inhalation-exhalation cycle; and (4) for monitoring the animal's movements, in later experiments, a head-stage-mounted light bulb whose position in the chamber was detected with a TV camera.

In earlier experiments, units were recorded single-ended with reference to a skull screw. Signals were amplified, filtered (bandpass, 300 $\mathrm{Hz}-5 \mathrm{kHz}$ ), and recorded directly onto audiotape along with trial event artifacts. In later experiments, units were recorded differentially between microwires, amplified, filtered, and then passed through a window discriminator. Spike events were asynchronously latched into a digital buffer that was sampled at $1 \mathrm{kHz}$ and stored as spike time-of-arrival on a computer disk. Action potential waveforms were monitored continuously during recording. The reliability of spike detection and isolation was monitored at the same time by comparing an audio artifact of window detection to the waveform observed on the oscilloscope. Data were not used if multiple waveforms could not be discriminated by the window detectors. EEG and sniffing signals were amplified and filtered at $0.3-40 \mathrm{~Hz}$, sampled at $100 \mathrm{~Hz}$ by an $\mathrm{A} / \mathrm{D}$ converter, and stored on computer disks. Animal location was digitized at $10 \mathrm{~Hz}$ as $X$ and $Y$ spatial coordinates (see Fig. $1 A$ ) and stored on the computer disk. All these data were collected from 2 sec before the trial initiation signal to $20 \mathrm{sec}$ after onset of the nose poke for a total period of up to $40 \mathrm{sec}$.

Data analyses. All units were evaluated for a number of physiological properties. Average firing rate was determined over the sum of all trial data-collection periods for each cell. The existence and phase of thetarelated firing was determined for each spike by measuring the period between negative peaks of the EEG (digitally filtered to 4-20 Hz) surrounding the spike. The spike was considered to have occurred during theta if the EEG cycle period was $100-250$ msec. The phase was determined as the relative location of the spike between theta peaks. A cell was considered theta-related if it fired at least $50 \%$ more often in theta. It was considered phase-related if the distribution of the incidence of phases significantly $(p<0.01)$ modeled an ideal sine-wave distribution (Kuperstein et al., 1986).

The nature of stimulus presentations and task contingencies resulted in a stereotyped sequence of behaviors elicited by the rat on each trial. In a combined attempt to explore the behavioral correlates of unit activity at any phase of the task and to test the reliability of specific 
behavioral correlates observed, we developed a 2-stage battery of post hoc analyses. Stage I was a search for synchronization of unit activity with salient trial events. In addition, place-fields were determined by a survey of unit firing rate as a function of location of the animal regardless of ongoing behavior. In stage II, we explored in detail both the behavioral and spatial parameters influencing unit activity related to that event which best synchronized firing as identified in stage $\mathrm{I}$. This was done using a combination of raster display and averaging techniques, and a reconstruction of movement paths and unit firing locations around the time of the trial event.

\section{Stage I}

Perievent histogram profile. This analysis focused on a series of 7 repetitive events that could be identified during each trial by the animal's location and behaviors related to experimenter-generated stimuli. The time periods around each of these covered the entire sequence of significant trial events. The events were (1) tone-off, defined as the offset time of the tone signaling the beginning of a trial; (2) move-to-port, defined as the initiation of movement (minimally $16 \mathrm{~cm}$ in $0.5 \mathrm{sec}$ ) toward the odor-sampling port following the end of the ITI; (3) nose poke, defined as the time when the rat's nose broke the photocell beam in the odor-sampling port; (4) response, defined as the termination of the poke by early nose withdrawal $(R-)$ or completion of the 2 sec $R+$ poke; (5) turn-to-cup, defined as the initial movement $(4 \mathrm{~cm}$ in $0.5 \mathrm{sec})$ away from the port made while turning the head toward the reward cup; (6) move-to-cup, defined as the initiation of a larger movement (minimally $16 \mathrm{~cm}$ in $0.5 \mathrm{sec}$ ) made while running across the arena toward the reward cup; and (7) cup-arrival, defined as the approach to within $4 \mathrm{~cm}$ of the reward cup. Perievent histograms of unit activity were constructed for $2 \mathrm{sec}$ before and after each event for every cell. The trial periods represented in each of these $4 \mathrm{sec}$ histograms overlapped considerably with periods associated with successive trial events. The sequence of histograms was normalized for each cell. Histograms were compared to determine the extent to which unit firing could be timelocked to particular events. Histograms could not be normalized across cells because of the large range of variation in average firing rates. Further detailed examination focused on that event which produced the maximum peak firing rate and minimal temporal dispersion of the unit activity envelope, whether the firing was simultaneous with the event or at some latency from it. For each unit, the peak event-locked firing was calculated as the ratio of the maximum firing rate observed in the perievent histogram profile versus the overall mean firing rate of the cell.

Place-fields. To evaluate location-related unit activity without regard to ongoing behavior, firing rates were calculated for each entry into 16 equal-area places on the floor of the behavioral chamber (Fig. 1A) and also, as a separate place, when the rat's nose was in the odor-sampling port. Data were sampled for the entirety of each trial period, lasting up to $40 \mathrm{sec}$ per trial, thus summing over all trial events and periods outside of the trial events described above for the entire session. The cell was judged to have significant spatial firing if at least 1 place was associated with an average firing rate at least twice that of the grand mean of the firing rates determined in the analysis. Places not visited at least 10 times were not considered. For cells with significant spatial firing, the place-field was defined as the combination of those places for which the firing rate was at least 1.5 times the grand mean. This definition of placefields usually resulted in well-defined regions of high firing rates bordered by regions of abruptly lower firing rates. Not all places within the arena were visited with equal frequency. Our data include primarily those places adjacent to the direct path between the odor-sampling port and the reward cup (see Fig. 1A). Places outside of that region were frequently disregarded from the analyses for lack of sufficient data.

\section{Stage II}

Perievent raster displays. Each analysis involved a display combining averaged sniff, theta, and location data, and a raster display of trial-bytrial unit activity with a summary perievent unit histogram, all timelocked to the onset of the trial event. In an effort to synchronize unit activity to the sniff or theta rhythms, the time-lock was adjusted to a peak of an inhalation or theta cycle nearby the trial event. Several stimulus and response combinations were examined to explore dependence of unit responses during the nose-poke period on stimulus quality, valence, and history, and response type. Cells that appeared to fire during turning and movement periods were studied for firing relation to move- ment onset and peak velocity. Place-field firing was examined with unit activity histograms time-locked to entry into the place-field. The trial circumstances influencing place-field firing were studied by comparing cell firing at different trial periods and under different trial outcomes.

Path-maps of movements and unit activity. In order to explore further the spatial aspect of unit firing during specific behavioral events, the movements of the rat during particular trial periods were reconstructed within an outline of the behavioral chamber. Points were plotted on the outline to represent the rat's location at $100 \mathrm{msec}$ intervals for 2 $\mathrm{sec}$ before and after the selected trial event. In addition, the number of spikes occurring during the time between location points was accumulatcd. Symbols were superimposed on each associated location point, with the size of the symbol reflecting the unit activity rate. Path-maps constructed for different trial events were compared to examine the detailed patterns of movements rats made in approaching the sampling port versus the reward cup, and during the nose poke under different stimulus conditions. Equal numbers of samples were taken from overlapping trials for each comparison. Because each rat developed stereotyped characteristic movement patterns for each trial event, it was impossible to equalize the number of location samples for each area of the behavioral chamber. Path-maps were not averaged over behaviors, nor were they normalized across areas in the chamber. Thus, this analysis should not be considered as equivalent to the analysis of place-fields as given above. Rather, path-maps provide a visualization of the location of the animal and associated unit activity around the time of that trial event associated with maximal unit activity.

\section{Results}

\section{Behavioral}

The experimental contingencies encouraged a stereotyped sequence of behaviors. Typically, the rat would sit near the middle of the chamber until the tone signaled trial initiation. Then it would rapidly approach the port, poke its nose in, and either maintain a relatively immobile stance on $S+$ trials or remove its nose on $\mathrm{S}-$ trials. Following an $\mathrm{R}+$, the rat would turn away from the port and usually run directly to the reward cup at the opposite end of the arena, satisfying the criteria for both the move-to-cup and cup-arrival events. Following an $\mathrm{R}-$, the rat would turn away from the port and either approach the reward cup, even though no water was given, or stop and wait for the next trial near the middle of the chamber (see Fig. $1 B$ for individual trial examples). In the case of an $\mathrm{R}-$, the move-toport and/or cup-arrival event criteria were sometimes not met. Discriminative performance was usually $80-90 \%$ in both the 2 and 8 odor versions of the task.

\section{Sniffing and the theta rhythm}

As reported in an earlier study of odor discrimination and reversal, the hippocampus exhibits a pattern of large-amplitude, higher-frequency $(7-10 \mathrm{~Hz})$ rhythmic activity during approach to the port or reward cup and a lower amplitude and frequency (5-7 Hz) theta during stimulus sampling (see individual trial examples, Fig. $1 B$; cf. Macrides et al., 1980). In addition, rats typically engage in a bout of 3-6 sniffs at 5-7 Hz during stimulus sampling and prior to arrival at the reward cup. Although rats are relatively immobile during stimulus sampling, small head movements, including head rotation or extension of the nose further into the port, often occur during the production of the $\mathrm{R}+$ response (see $X$ and $Y$ averages in Fig. $1 C$ ). Although locomotor activity is absent, the observation of these head movements, as well as other voluntary motor activity associated with investigatory sniffing, suggests that stimulus sampling in this task may fit best into Vanderwolf's (1971) type I behavioral category.

During both cue sampling and cup approach, sniffing cycle and the theta rhythm were synchronized. Those trial events 
A

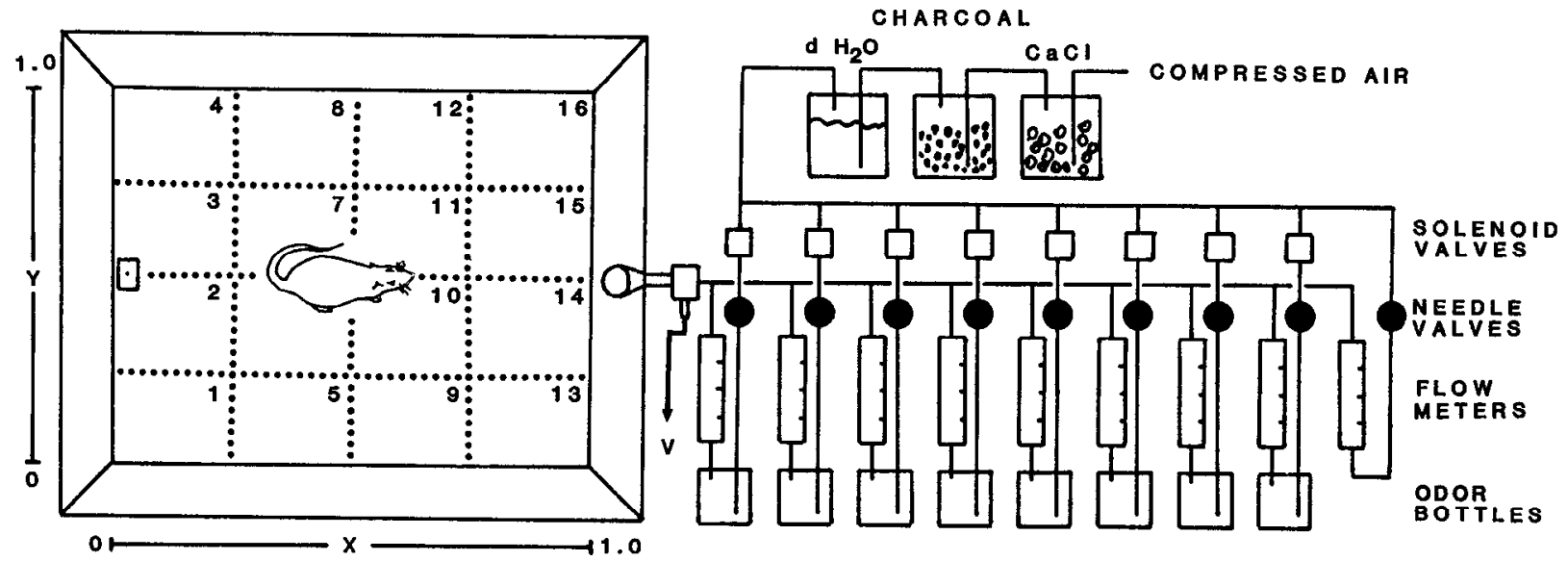

B

TIME(1s)

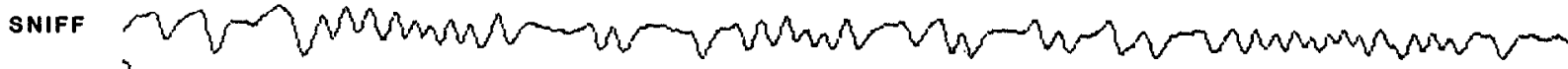

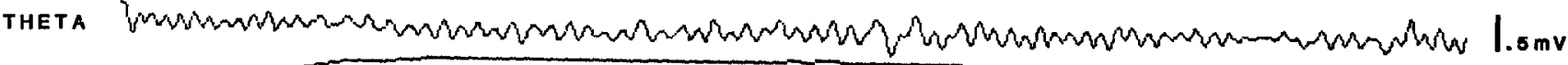

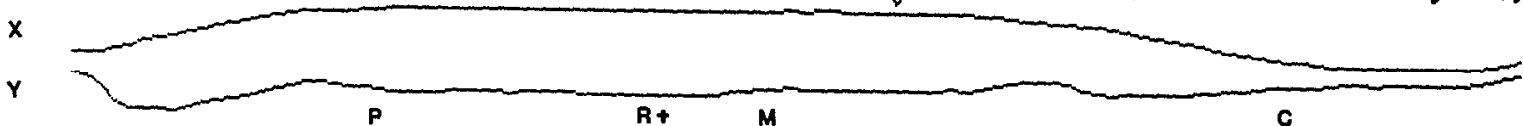

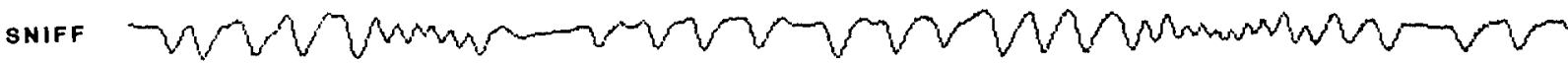

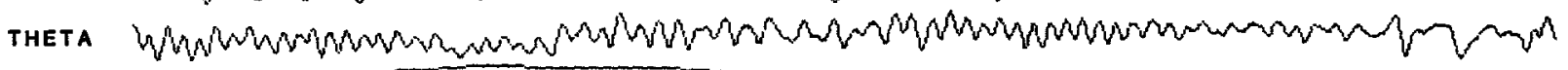

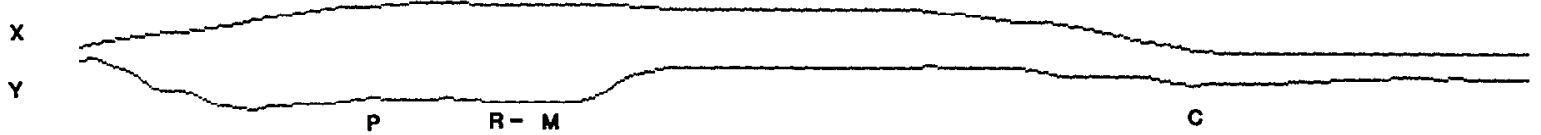

C

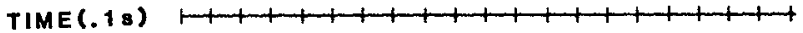
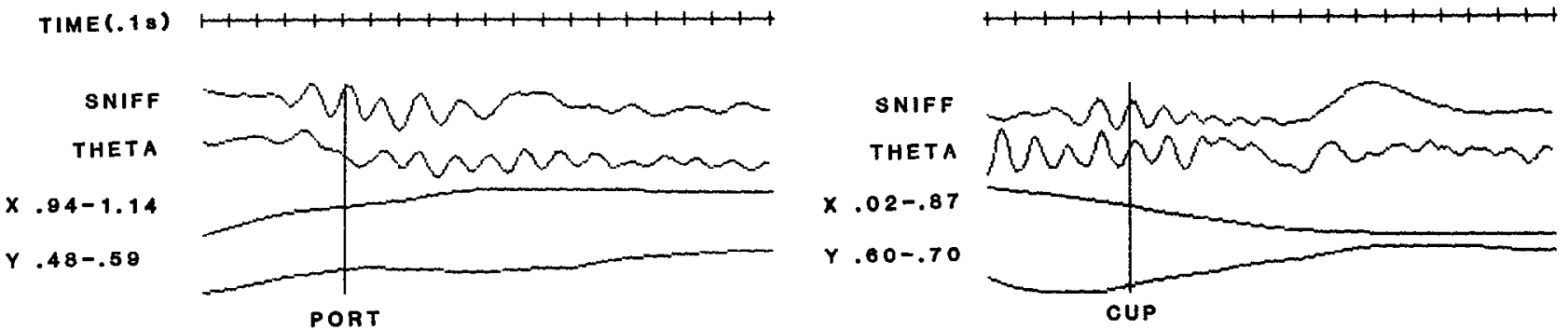

Figure 1. Apparatus and sequence of behaviors performed by rats during odor discrimination training. $A$, Left: Behavioral chamber showing slanted walls with the reward cup below center of left wall and the odor-sampling port at center of right wall. Dotted lines indicate the 16 numbered areas (plus the sampling port) compared for place-field unit firing. $X$ and $Y$ spatial axes indicate relative distances along each axis determined by the TV coordinate system. Right: Eight channel olfactometer and final solenoid valve (connected to the sampling port) that directed flow to a vacuum dump $(V$ ) except during the cue-sampling period. $B$, Tracings of sniffing (inhalation up), hippocampal theta rhythm (negative up), and movements of rat (position 0 at bottom for each) during 2 individual trial examples. Upper traces: Typical slow inhalation cycle during approach to the odor port is followed by a sniff bout and synchronized theta cycles at the onset of the nose poke $(P)$. The sniff bout ends before the complete $2 \mathrm{sec}$ nose poke $(R+)$; then the rat turns and starts to move $(M)$ towards the reward cup. Just before arrival at the cup (C) the rat executes another investigatory sniff bout. Lower traces: Similar sequence of events for trial with incomplete nose poke $(R-)$. $C$, Example of averaged sniff, theta, and movement records time-locked to the peak of the first inhalation after the onset of the nose poke (left) and the peak of the third inhalation before arrival at the reward cup (right). Left: Sniff bout includes about 5 synchronized sniff cycles. Theta cycles synchronize 120 msec after $(r=$ $0.767, p<0.001$ ) and outlast the sniff bout. Right: Sniff cycle entrains to the ongoing theta rhythm, but the correlation method reveals that theta is best synchronized $130 \mathrm{msec}$ following the sniff cycle $(r=0.579, p<0.001)$. In this and successive figures, $X$ and $Y$ ranges are expanded to show details of movements during a select period of the trial. The coordinate range for each is given at the left of the tracings. Values greater than 1.0 indicate a location of the head beyond the boundaries of the arena floor. 


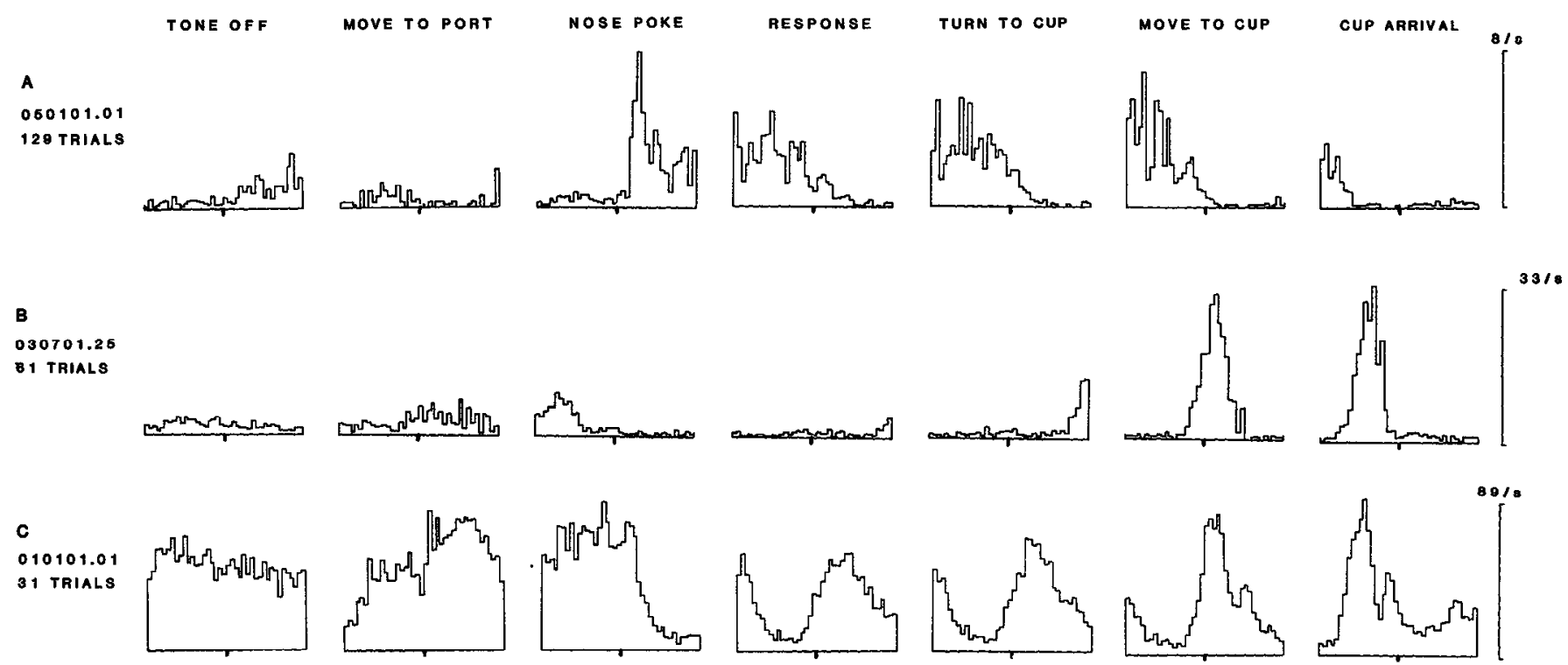

Figure 2. Perievent histogram profiles for an example of each major cell type observed. Profiles are labeled at the left by unit identification and number of trials for data collection. Each histogram plots firing rates in $100 \mathrm{msec}$ bins for $2 \mathrm{sec}$ before and after onset (tic mark below histogram) of indicated trial events. $A$, Cue-sampling cell that shows best synchronization to the nose poke. High firing rates time-locked to other events represent some of the same time period but with less clear synchronization of unit activity. $B$, Goal-approach cell that shows a small firing increase prior to arrival at the port (nose poke) and maximal firing with equivalent synchronization to both onset of movement towards the reward cup and arrival at the cup. $C$, Theta cell that shows highest firing during approach to both the sampling port and the reward cup, and minimal firing in the middle of sampling and after arrival at the cup.

differed in that, during odor sampling, the sniff bout preceded the synchronized theta rhythm, but, during approach to the reward cup, the sniffing entraincd to the ongoing theta rhythm. However, in both cases, our analyses indicated that the correlation of sniffing and theta is best when sniffing is considered to lead the theta rhythm by about 1 cycle. These phenomena are illustrated by time-locking both the sniff and EEG signals to the peak of the first inhalation after entry of the nose into the port or to the peak of an inhalation prior to arrival at the location of the cup (Fig. 1C). By averaging several trials, reliable bouts of sniffing and synchronized theta are revealed. In this study, the latency at which the theta rhythm follows sniffing was computed by comparing the coefficients derived from Pearson correlations of $0.5 \mathrm{sec}$ samples of both signals. The sniff signal for each of 50 comparisons and the theta signal for the first comparison began at the peak of the first inhalation. Other theta samples began at successive $10 \mathrm{msec}$ steps later into the trial. The consequent temporal shift of theta backward in time that yielded the maximum correlation coefficient was regarded as the preferred latency of the theta rhythm to sniffing for that session (cf. Winson, 1974). The maximal correlation coefficients ranged from 0.73 to 0.90 at shifts of $120-160 \mathrm{msec}$. During approach to the reward cup, even though the synchronized theta rhythm begins prior to the sniff bout, maximal correlation was achieved when the theta rhythm was considered to follow the sniff cycle by the same latency as during stimulus sampling (see Fig. 1C).

\section{Physiological characterization of units}

Spike waveform and firing repertoires were studied to assign units to "complex spike" and "theta" cell categories originally described by Ranck (1973) and Fox and Ranck (1981) and subsequently observed by several investigators (O'Keefe, 1976; Berger et al., 1983; Rose, 1983; Christian and Deadwyler, 1986).
Most units recorded in this study had the characteristics typical of complex spike cells (see Table 1). They had long-duration (0.5-1.0 msec) negative extracellular spikes, and many exhibited complex spikes, although their occurrence was not reliable for use as a categorization variable. The average firing rate for these cells was quite low, and some cells often did not fire for several seconds. However, synchronization of firing to selected trial events sometimes revealed associated bursts exceeding 30 spikes/ sec for short periods (all action potentials in a complex spike were counted). Some units increased firing during theta, but typically by less than twice the non-theta firing rate. In addition, nearly all these units were recorded in the CA1 or CA4 pyramidal cell layers, as confirmed by post hoc histological examination. We also collected data from a small number of theta cells characterized by their short-duration (0.2-0.4 msec), high average firing rate, and localization usually outside of the py-

Table 1. Physiological characterization and event-locked firing of cell types

\begin{tabular}{|c|c|c|c|c|}
\hline \multirow[b]{2}{*}{ Parameter } & \multicolumn{4}{|l|}{ Cell type } \\
\hline & $\begin{array}{l}\text { Cue- } \\
\text { sampling }\end{array}$ & $\begin{array}{l}\text { Goal- } \\
\text { approach }\end{array}$ & Theta & Other \\
\hline$N(\%)$ & $17(14.8)$ & $69(60.0)$ & $11(9.5)$ & $18(15.7)$ \\
\hline \multicolumn{5}{|c|}{ Average firing rate $(\mathrm{Hz})$} \\
\hline Mean $\pm \mathrm{SE}$ & $2.8 \pm 1.1$ & $2.7 \pm 0.8$ & $16.4 \pm 3.0$ & $1.4 \pm 0.3$ \\
\hline Range & $0.1-8.9$ & $0.1-6.8$ & $7.1-27.1$ & $0.2-3.2$ \\
\hline$\%$ Theta related & 25 & 33 & 100 & 21 \\
\hline$\%$ Phase related & 28 & 46 & 86 & 14 \\
\hline \multicolumn{5}{|c|}{ Peak event-locked firing } \\
\hline Mean $\pm \mathrm{SE}$ & $3.2 \pm 0.5$ & $5.1 \pm 0.5$ & $2.0 \pm 0.2$ & - \\
\hline Range & $1.3-8.0$ & $1.5-10.1$ & $1.7-3.0$ & - \\
\hline
\end{tabular}


ramidal cell layers. We found it useful to segregate cells by firing rate in relation to the presence or absence of theta activity and by preferential firing according to theta phase (see Table 1).

No differences in cell properties were observed in CAl versus CA4. Complex spike and theta cells tended to group separately at any particular penetration site, as might be expected from Fox and Ranck's (1975) localization of these cell types in separate hippocampal laminae. Otherwise, the behavioral correlates of complex spike cells recorded simultaneously from electrodes within $1 \mathrm{~mm}$ of each other bore no obvious relation to one another. In later experiments, usually more than one cell (maximum of 8) was recorded during the same trial block. Typical recording sessions included cells with variations on both of the major behavioral correlate types described for complex spike cells below. Thus, it is unlikely that the cells reported here were all firing in relation to the general arousal or motivational state of the animal.

\section{Behavioral correlates of unit activity}

In all, 115 units were held for sufficient time to allow characterization. It is important to note that not every unit had a behavioral correlate, and some trial events failed to synchronize neuronal activity. For 17 units, we uncovered no systematic behavioral correlate. One cell included in the "other" group in Table 1 had a clear place-field, but its firing was synchronized to no specific trial event tested. No units fired in relation to the trial-initiation tone offset, and none was best synchronized to either the R+ or R- response event. However, activity was synchronized to other trial events in $86.3 \%$ of the units. The behavioral correlates of these cells could be organized into 3 major categories designated "cue-sampling" cells, which increased firing during the nose-poke period; "goal-approach" cells, whose firing was synchronized with movements towards and arrival at the sampling port or the reward cup, or both; and "theta" cells, which had high avcrage rates and fired maximally during all approach periods. A perievent histogram profile for an example of each unit category is presented in Figure 2. Timelocking to these behaviors resulted in peak event-locked firing rates averaging 3-5 times higher than the average unit firing rate (Table 1). The sections below describe the properties of these cells and indicate that further characterizations of the synchronization event result in even better time-locking of unit activity.

\section{Cue-sampling cells}

The typical perievent histogram profile for this type of unit revealed increased firing beginning $300 \mathrm{msec}$ or later into the nose-poke period and maximal synchronization of firing to the beginning of the nose poke (Fig. $2 A$ ). Firing was always more poorly locked to the response, defined as offset of the stimulus sampling period, regardless of stimulus type.

The most salient qualities revealed in the analysis of a cuesampling cell are shown in Figures $2 A$ and 3 . This cell increased firing beginning $300 \mathrm{msec}$ after the peak of the first inhalation after the nose-poke onset. Maximal firing, often in a rapid burst, coincided roughly with the rising wave of the third or fourth complete inhalation into the sampling period. Typically, the cell fired with only a single spike or burst associated with one of the perievent histogram peaks. Stimulus sampling was characterized by synchronized sniff and theta cycles, although this indicator of investigatory sniffing was not sufficient to predict increased cell firing. The unit did not fire during the period of synchronized sniffing and theta rhythm on arrival at the reward cup.

The magnitude of response in sampling cells was strongly influenced by stimulus conditions and training, despite similar synchronization of sniff and theta cycles under all conditions. As shown in the series of raster displays generated from the same data set on the cell in Figure 3A, firing was much greater during sampling of $S+$ than $S-$ stimuli. The predominance of firing for $\mathrm{S}+$ over $\mathrm{S}-$ was seen in $95 \%$ of this class of cells. Furthermore, in those cases where $4 \mathrm{~S}+$ and $4 \mathrm{~S}$ - odors were used, responses for all $\mathrm{S}+$ stimuli were equivalent and larger than responses observed for all $\mathrm{S}-$ stimuli. Thus, differences in unit responses were related to cue valence rather than odor identity.

Two findings indicate that the unit response in sampling cells was also influenced by past experience. First, unit responsiveness increased during the training session, and did so to a greater extent for $\mathbf{S}+$ trials than for $\mathbf{S}-$ trials. In the example shown in Figure $3 A$, examination of the sequence of raster lines, representing the series of trials, reveals the growth of unit firing over approximately the first third of the trials. Second, stimulus valence of the immediately previous trial influenced unit response on the current trial. Comparison of Figure $3 B$, left and right, shows that firing was much greater when the stimulus on the preceding trial was $\mathbf{S}-$ than if it was $\mathbf{S}+$, even though the stimulus on the current trial was equally likely to be $\mathbf{S}+$ or $\mathbf{S}-$ in each panel. In addition, the effects of current and prior stimulus valence were additive. Figure $3 C$ shows that maximal unit response was obtained in trial sequences of $S+$ preceded by $S-$, and minimal unit response in trial sequences of $S-$ preceded by $\mathrm{S}+$. Other sequences were characterized by intermediate unit responses. These unit response variations could not be related merely to the number of trials since last reward. Most sampling cells demonstrated this "positive contrast" effect; none showed the opposite.

\section{Goal-approach cells}

This category of cells fired maximally time-locked to arrival at the odor port (port-approach cells) or reward cup (cup-approach cells). Some approach cells fired during both the port- and cupapproach periods, but preferentially during one of them, as in the example shown in Figure $2 B$. The activity of many cells was equally well synchronized to turning or movement towards the port or the cup. A histogram profile for a cup-approach cell that fired maximally at the initiation of a rapid movement toward the cup is shown in Figure $2 B$. Note that the firing is equivalently synchronized to arrival at the reward cup, with a peak of activity $700 \mathrm{msec}$ in advance of arrival. Many of these cells fired maximally in 3-5 bursts tightly coupled with the ongoing theta rhythm (Figs. $4 A ; 5, B, C$ ).

Individual port-approach cells fired at different latencies prior to arrival at the odor port. An example of a port-approach cell that fired well before arrival at the port is shown in Figure $4 A$. A distinct subclass of port-approach cells showed increased firing at $200 \mathrm{msec}$ before or after nose-poke onset (mean latency, $30 \mathrm{msec}$ before nose poke). Despite increased activity during the stimulus sampling period, none of these units demonstrated strikingly greater firing during $\mathbf{S}+$ versus $\mathbf{S}-$, unlike cuc-sampling cells. An example of this cell type is shown in Figure 4, $B, C$. As described in Materials and Methods, stimulus delivery does not begin until the nose poke is executed, so odors do not 

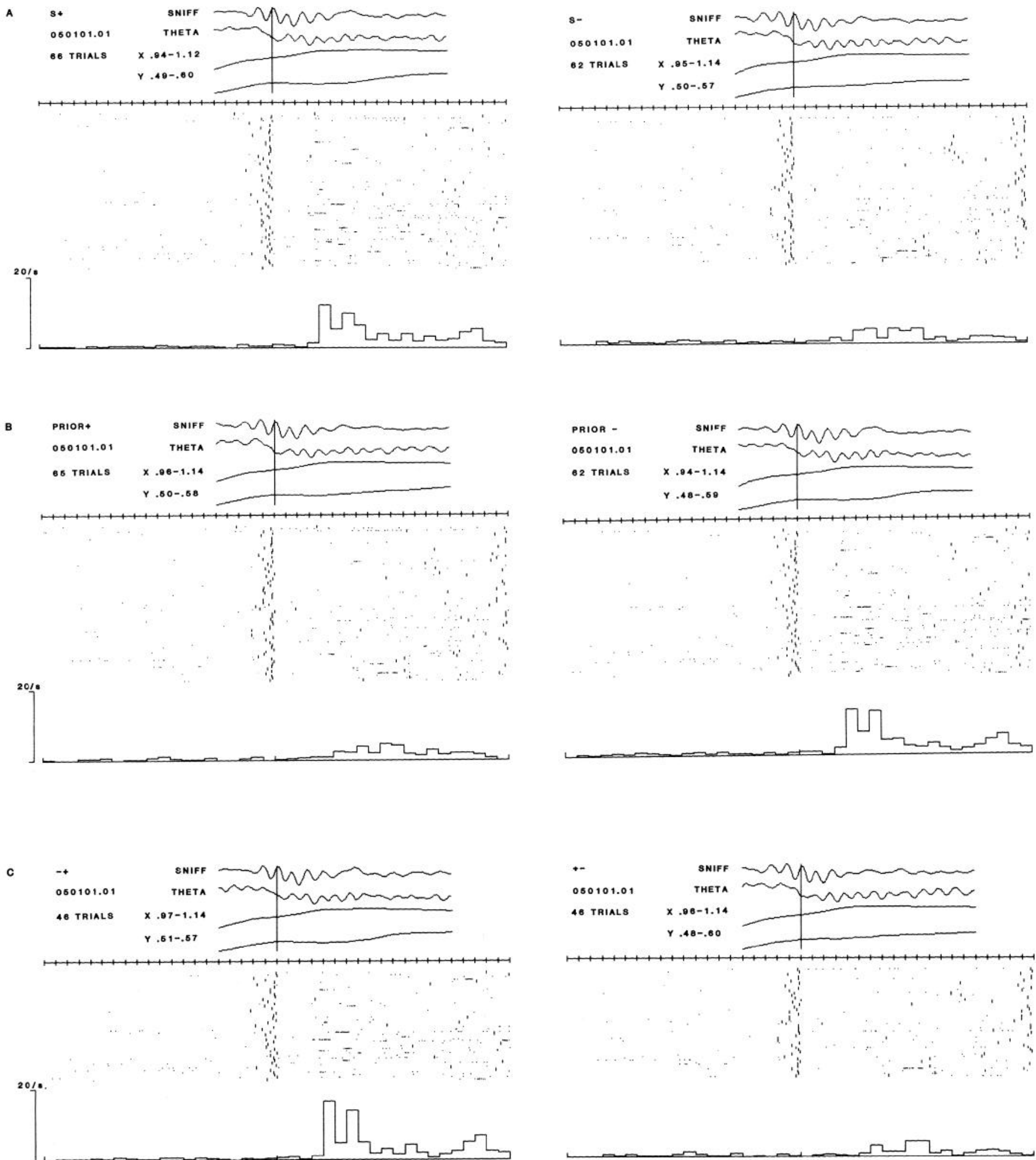

Figure 3. Detailed analysis of the cue-sampling cell shown in Figure $2 A$. Sniff, theta, movements, and unit firing are time-locked to the peak of the first inhalation after the onset of the nose poke (vertical line through slow wave and movement tracings). Tic marks in the time line indicate $0.1 \mathrm{sec}$ intervals. The nose-poke onset is indicated by a vertical bar in each trial raster line; in some trials, a second vertical bar indicates the time of completion of $\mathrm{R}+$ or $\mathrm{R}$ - response. Sniffing, theta, and their synchronization are equivalent across all analyses. $A$, Response is greater for an $\mathrm{S}+$ odor (left) than for an $\mathrm{S}-$ odor (right). Note the firing burst in some responses during $\mathrm{S}+$. B, The unit response is smaller if the stimulus on the immediately prior trial was $\mathrm{S}+($ left $)$ rather than $\mathrm{S}-($ right $)$. Half of the current stimuli are $\mathrm{S}+$ and half are $\mathrm{S}-$ in each panel. $C$, The largest response is for $\mathbf{S}+$ when the prior stimulus was $\mathrm{S}-($ left $)$. Conversely, the smallest response is for $\mathrm{S}-$ when the prior stimulus was $\mathrm{S}+($ right $)$. 

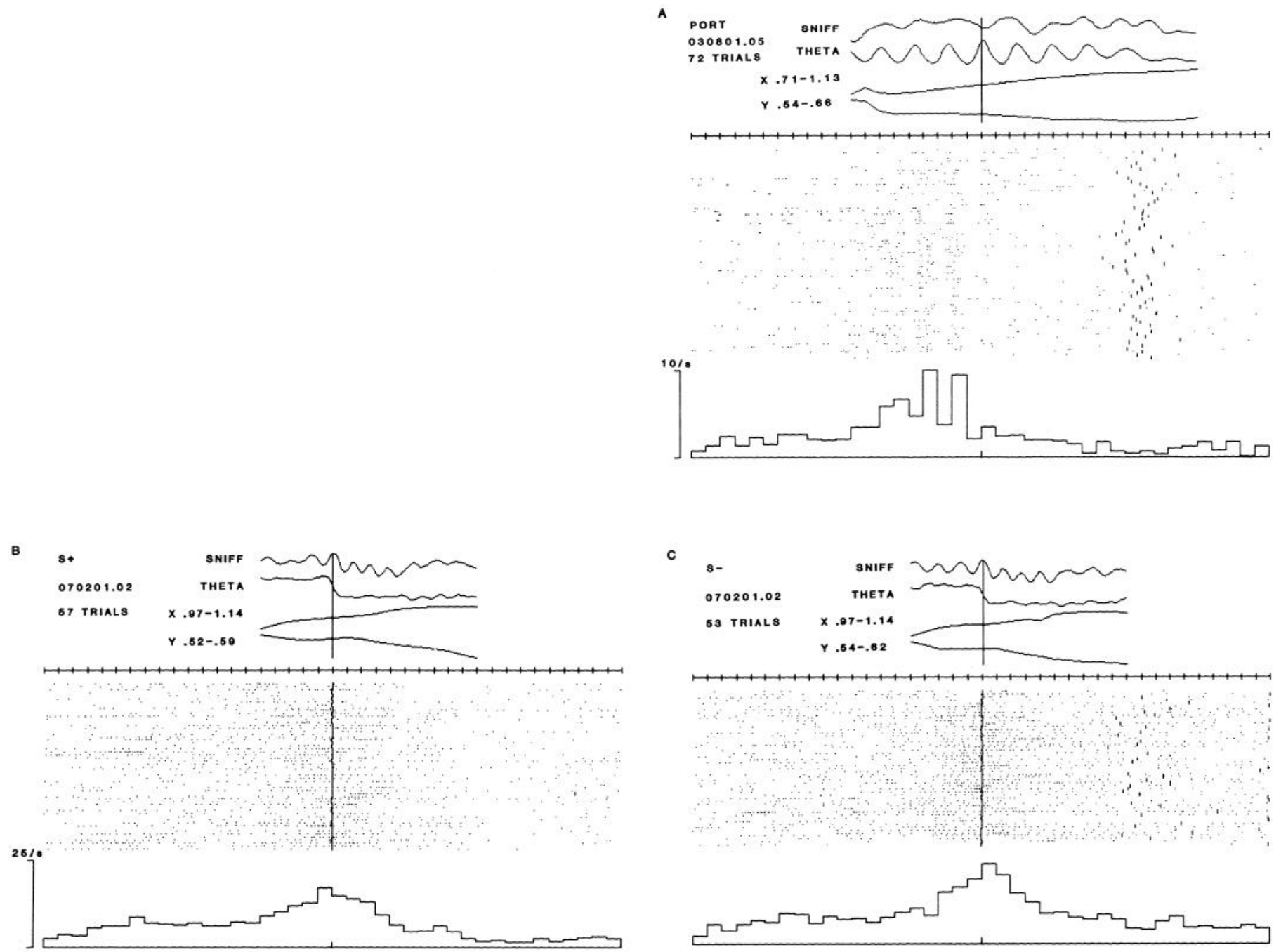

Figure 4. Detailed analyses of 2 port-approach cells. In the raster lines, the initial vertical bars represent onset of the nose poke; a second bar, when present, indicates nose-poke offset. $A$, In this cell, firing is synchronized to initial movements towards the sampling port. All measures are time-locked to the negative peak of the fifth theta cycle before arrival at the port. Note the bursts of unit activity associated with the theta rhythm beginning at sudden changes in $X$ and $Y$ positions. $B$ and $C$, This cell fired simultaneously with the final orientation of the nose into the sampling port. All measures are time-locked to the onset of the nose poke. Although the unit response continues into the cue-sampling period, its magnitude is equivalent for $\mathrm{S}+(B)$ and $\mathrm{S}-(C)$ trials.

reach the nasal epithelium until at least $100-200 \mathrm{msec}$ after nose-poke onset and peak firing in these cells. Thus, it is not surprising that cells which fire maximally at the nose poke do not differentiate stimuli. Rather, their firing seems related to the final orientation of the nose into the sampling port.

Individual cup-approach cells also demonstrated considerable variation in the latency of maximal activity related to arrival at the cup, as well as onset of movement. Some fired late in the period of approach to the cup and continued to fire through reward consumption. Figure $5, A-C$, shows raster displays of 3 cup-approach units that fired at different latencies after the onset of movement towards the cup and prior to arrival at the cup. These cells were usually better synchronized to movement onset than to maximal velocity during the approach. Comparison of onset of the firing bursts with movement tracings suggests that these cells may fire in relation to specific transitions in movement (see Fig. 5).

The distribution of peak firing latencies across all cell types indicates a considerable range of firing onsets in each trial pe- riod. Figure 6 shows, successively from left to right in a composite histogram, the incidence of port-approach units firing maximally at different latencies prior to the rat's arrival at the port, the incidence of cue-sampling units firing maximally at different latencies following nose-poke onset, and the incidence of cup-approach units firing maximally at different latencies prior to arrival at the cup. Firing increases predicted arrival at the port or cup at a range of times up to $2 \mathrm{sec}$ in advance of the rat's arrival. Firing latency in cue-sampling cells also varied considerably in relation to onset of the nose poke.

\section{Place-field firing}

Of 47 cells examined for spatial firing, 20 units demonstrated place-fields. These included 2 of 8 cue-sampling cells and 17 of 38 goal-approach cells. One cell was not otherwise classified (see above). The distribution of place-fields disproportionately represented places in the middle of the chamber, with a bias towards areas nearer the port, where port-approach and cup-approach movements were usually initiated (Fig. 7). For the 2 cue-sam- 

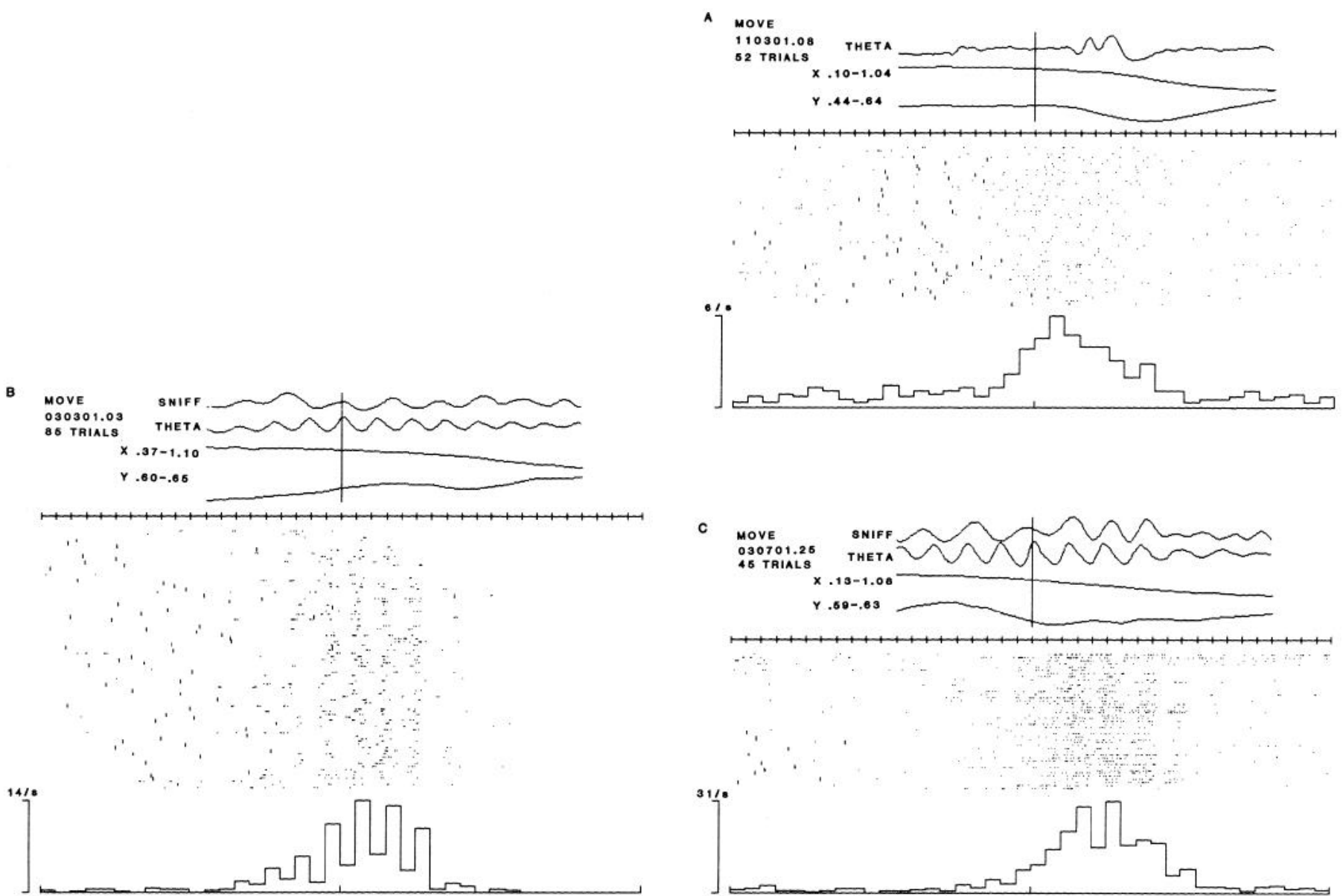

Figure 5. Detailed analyses of 3 cup-approach ceiis. In the raster lines, vertical bars represent completion of $\mathrm{R}+$ or $\mathrm{R}-$ response. Analyses shown in $A, B$, and $C$, respectively, are examples of cells that fire at successively longer latencies after onset of movement towards the cup. The data in $B$ and $C$ are time-locked to a negative theta peak within the maximal firing period; the cell in $A$ did not fire in relation to the theta rhythm. $A$, Cell that fired maximally at the initiation of movement as indicated by $X$ and $Y$ coordinate changes. $B$, Cell that fired during maximal initial movement towards the cup. All measures are time-locked to the second negative peak of the theta rhythm before the initiation of movement. $C$, Cell that fired at end of the initial movement towards the cup. All measures are time-locked to the first negative peak of the theta rhythm before the initiation of movement. The perievent histogram profile for this cell is shown in Figure $2 B$.

pling cells, the place-field included only the sampling port and not the areas just outside of the port. High-resolution path-maps indicated largely overlapping positional movements of the head during the nose poke on $\mathrm{S}+$ and $\mathrm{S}-$ trials (Fig. $8 A$ ). Like other cue-sampling cells, firing in these cells was synchronized to the nose poke and influenced by odor valence and history, as described above for sampling cells. One might expect that all cuesampling cells should have place-fields in the port, but animals tend to perform many brief nose pokes, associated with low firing rates, outside the designated cue-sampling period; in most cases, these data samples reduce the average firing rate associated with the port area to levels below that of the place-field criterion.

Both raster displays and path-maps were used extensively to compare location- and behavior-related firing of goal-approach cells. Raster displays time-locked on entry into the place-field for 2 of the previously discussed (Figs. 4A, 5C) examples of approach cells are shown in Figure 9. Detailed examination in some cases revealed equivalent unit firing synchronizations with movement onset and entry into a cell's place-field, but in other cases, firing was more tightly correlated with movement. Spatial firing in approach cells was strongly influenced by task circum- stances. All goal-approach cells with place-fields were much more active upon entry into the place-field during one period in the trial, i.e., either the port-approach period (Fig. 9A, prepoke) or the cup-approach period (Fig. $9 B$, postresponse), as might be expected by their approach correlate. In addition, cupapproach cells fired upon entry into the place-field preferentially during $\mathrm{S}+\mathrm{R}+$ trials rather than during other trials in which no reinforcement was delivered (Fig. 9C). Responses were not affected by the stimuli or outcomes of previous trials.

Path-maps indicated that the rats often followed separate but intersecting trajectories towards the sampling port and reward cup. The path for each of these behaviors was highly stereotyped but distinct for each animal. The port approach often originated from different locations, but the final movements converged onto the same path on most trials (Fig. $8 B$, left). After completion of the nose poke, rats usually moved directly along a stereotyped path, contiguous with that of the main port approach, towards the reward cup (Fig. $8 B$, right). On nonrewarded trials, rats sometimes turned away from the port in a different direction, as in a few of the trials shown in the example in Figure $8 B$ (right). Most goal-approach cells fired primarily during one section of the path taken towards the port or cup. Cells that 


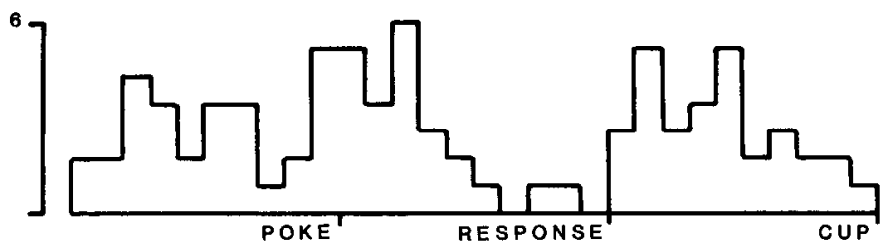

Figure 6. Incidence of units with different peak firing latencies (in 200 msec bins) at times before onset of nose poke in port-approach units, after onset of nose poke in cue-sampling units, and prior to the rat's arrival at cup in cup-approach units.

increased firing rate during both port- and cup-approach periods often did so within spatially contiguous and directionally opposing segments of their paths (Fig. $8 B$ ). Other cells fired maximally in spatially discontiguous arcas whcre port-approach or cup-approach movements were initiated. Figure 10 shows one cell that fired maximally in discrete regions where the rat began its run from an area near the reward cup towards the port (left), and where the rat left the port to approach the cup (right). Note that the combined paths formed a "figure eight" intersecting at both extremes and in the middle. At each intersection, firing was largely restricted to one trial period, indicating behavioral dissociation of the firing locations. Data from cells that fired almost exclusively during one approach period also provide evidence of behavioral dissociations of firing in locations common to both approach periods. Figure 11 shows the patterns of movements and firing from 2 cells recorded simultaneously from separate electrode channels in the same session as the cell examined in Figure $8 B$. These 2 cells had complementary periods of activity. One cell fired in synchrony with the port approach, which began in various locations (Fig. 11A, left), and did not fire during cup approach even though the path to the cup passed through an area of high firing rate during port approach (right). The other cell fired primarily during the cup approach (Fig. 11B, right) and fired very little in the intersecting and contiguous regions during port approach (left).

Although continuous monitoring during data collection was performed to reject collection of data from multiple units, it is possible that the action potentials of different neurons with similar waveform could have been misinterpretated as the activity of a single unit. This could account for the observation of multiple behavioral or spatial correlates, such as cells that appeared to have both port- and cup-approach correlates (e.g., Fig. 10). Multiunit recording cannot, however, account for the observation of behavioral selectivity of spatial firing in these cells or in cells with only a single behavioral correlate (e.g., Fig. 11).

Finally, it is important to note that 21 of the 38 approach cells studied for spatial firing had no recognizable place-field. Some of these negative results may have been due to our method for place determination, which is not as sensitive as some currently used (Muller et al., 1983). Some cells without a placefield fired at very slow average rates, possibly resulting in insufficient data to identify a place-field. However, many had avcrage firing rates higher than those of simultaneously recorded cells with place-fields. Interestingly, goal-approach cells with place-fields were more likely to be modulated by theta state $(76 \%)$ and phase $(65 \%)$ than those without place-fields (14\% fire relative to theta state, $29 \%$ relative to theta phase).

\section{Theta cells}

Firing of these cells gradually accelerated to rates exceeding 100/ sec during any period of maximal movement, such as port and

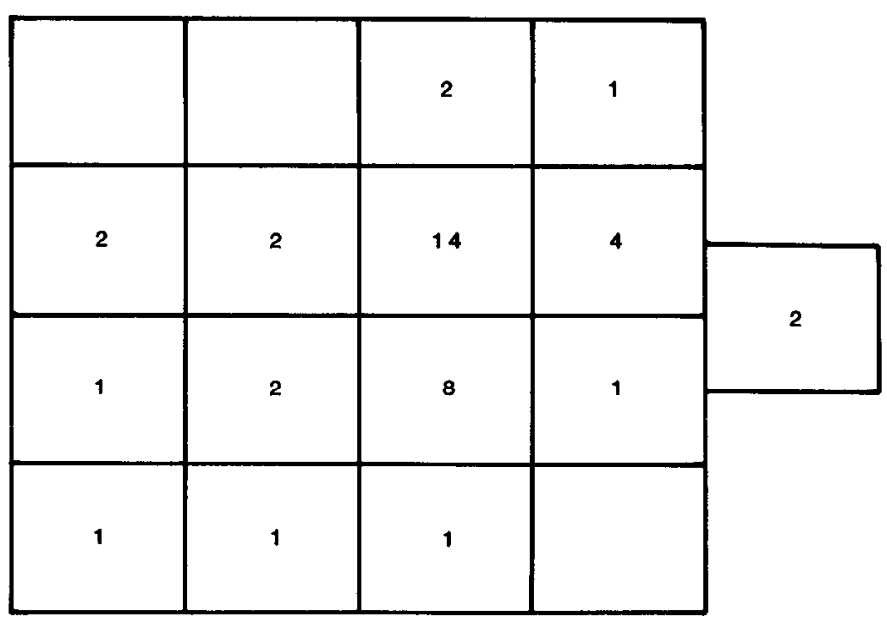

Figure 7. Incidence of areas included in a place-field by the 20 units in which place-fields were identified. The areas are in the same arrangement as that shown in Figure $1 A$, with the area at the extreme right representing the sampling port.

cup approach, and gradually slowed during relatively stationary periods, such as during nose poke and reward consumption. A perievent histogram profile of an example theta cell is shown in Figure 2C. A raster display of this cell shows its strong bursting closely related to the theta rhythm (Fig. 12).

\section{Discussion}

\section{Behavioral correlates of hippocampal physiology}

The combination of an odor-discrimination task with requirements for a repetitive sequence of spatially distinct behaviors allowed for examination of several previously reported correlates of hippocampal physiology in a single learning paradigm. The results confirmed observations of synchronization of the inhalation cycle and the theta rhythm during investigatory sniffing (e.g., Macrides et al., 1982), and unit firing in relation to learning (e.g., Berger et al., 1979; Deadwyler et al., 1979), sniffing (O'Keefe, 1976), appetitive movements (Ranck, 1973), and place (see O'Keefe, 1979). It is equally important that our examination of a range of salient task events revealed that some eventsspecifically, the trial-initiation signal, the odor quality of the stimulus, and completion of the rewarded or unrewarded response-were not associated with unit activity changes. The juxtaposition of all these findings in the same behavioral paradigm provides circumstances for useful speculation about the organization of functional qualities of hippocampal neurons. We measured success in defining a behavioral correlate as the degree to which unit activity could be synchronized with the onset of an independently defined event. Our preliminary characterizations using the perievent histogram profile revealed mean peak event-locked firing rates 3-5 times the average unit firing rate. Further qualifications of the synchronization event resulted in timc-lockcd pcak firing rates well over 10 times the average firing rate for many of these units.

These results led us to qualify 3 major categories of units in the hippocampal area CA1 and the hilus of the dentate gyrus: cue-sampling cells, goal-approach cells, and theta cells. The nomenclature of observed cell types refers to when cells fire and is not intended to imply that these cells are necessary for performance of the associated behavior. Rather, we suggest that these cells are processing some kind of information particularly 

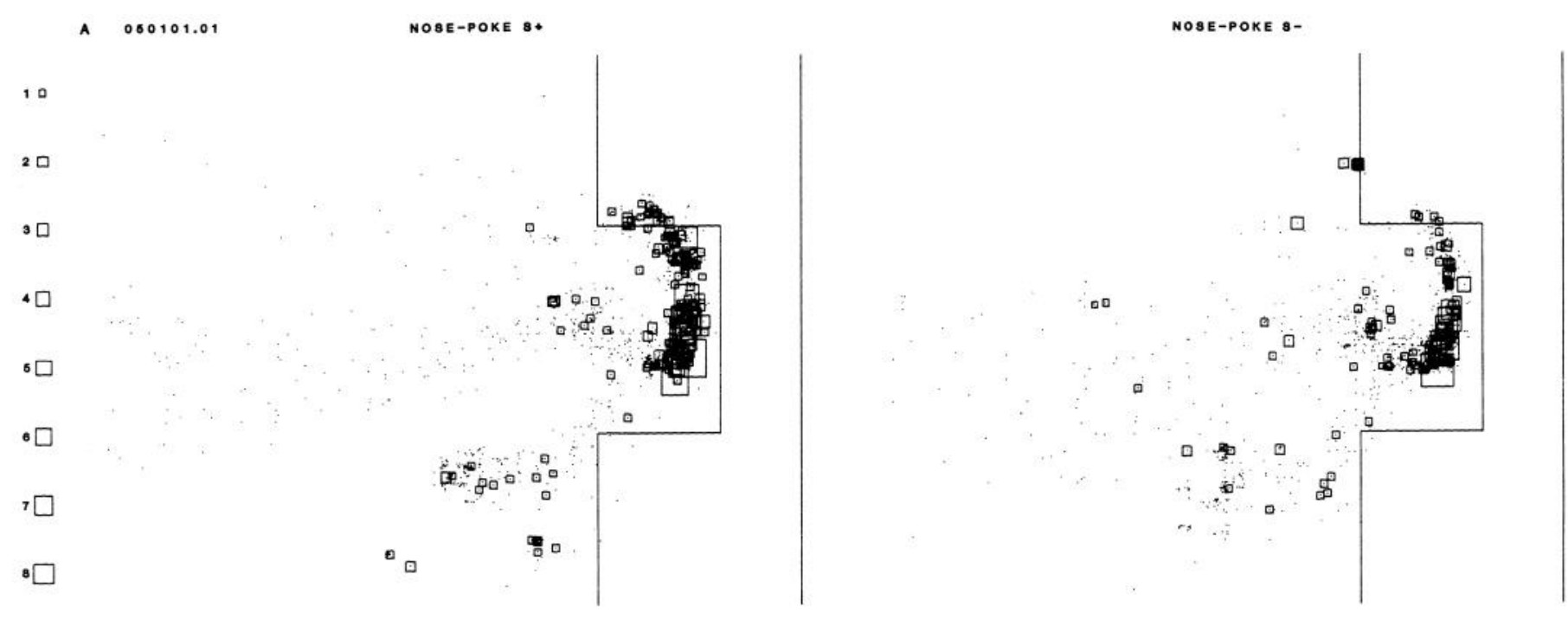

B
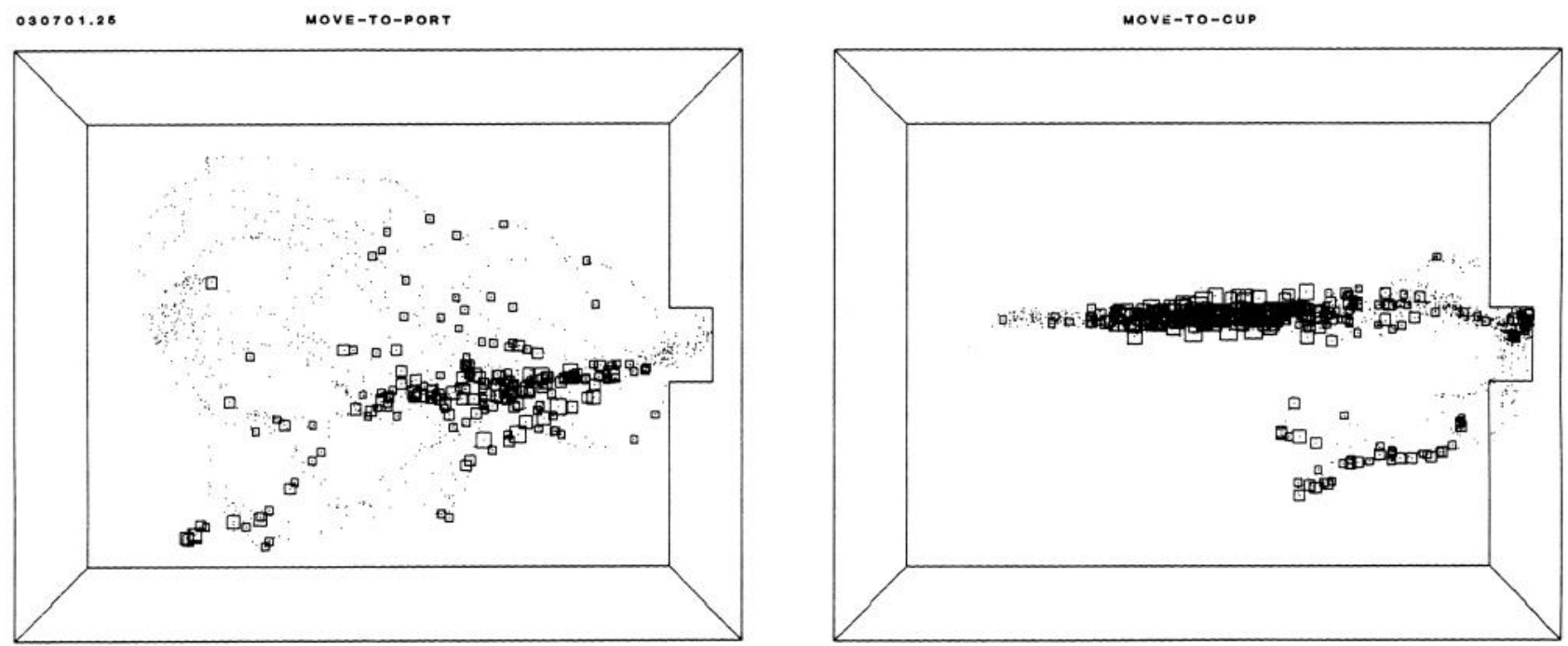

Figure 8. Path-maps showing animal movements and firing rates for the cue-sampling and goal-approach cells shown in Figure $2, A$ and $B$, respectively. Data are plotted on a diagram of the top view of the behavioral chamber, with the sampling port shown as a notch on the right wall and the location of the reward cup near the center of the opposite wall (shown at normal scale in $B$ and magnified to examine the area of the port in $A$ ). The path of the rat's movements for $2 \mathrm{sec}$ before and after onset of the nose poke are shown as points sampled at $100 \mathrm{msec}$ intervals. Unit activity, shown as squares of area proportional to the firing rate (in spikes per $100 \mathrm{msec}$ location sample) are superimposed on the location points. $A$, Close-up of the region near the sampling port shown as the notch in the lines at the right for the cue-sampling cell also examined in Figure 3. Note the neariy complete overlap of locations of maximal firing during $32 \mathrm{~S}+($ left) and $32 \mathrm{~S}-($ right) trials. B, Port approach (left) and cup approach (right) movement paths associated with the cell also shown in Figures $5 C$ and $9, B$ and $C$. Note that the paths and firing during these 2 periods overlap minimally, but are contiguous.

relevant during that period of the trial. Hippocampal system lesions do not impair acquisition of a simple odor discrimination (see Eichenbaum et al., 1986); thus, we do not suggest that cue-sampling cells are critical to sensory processing sufficient for simple discrimination performance. Similarly, hippocampal system damage does not eliminate approach behaviors, so we do not conclude that goal-approach cells are critical to simple appetitive behaviors.

The observation of clear behavioral correlates of unit activity in tasks not disrupted by lesions of the hippocampus presents a dilemma for interpretation of these data. Two explanations come to mind. One is that the hippocampus is not involved in the present task, and that its neurons demonstrate behavioral correlates that are encoded in other structures and reflected in hippocampal physiology. The other explanation is that the hip- pocampus participates in a representation of task experiences not required for simple discriminative responses. The existence of this representation might be revealed if the experimental contingencies of the task were changed. For example, striking spatial correlates of unit activity are seen both in maze tasks that require an intact hippocampal system for performance (McNaughton et al., 1983) and in those that do not (Olton et al., 1978). The hippocampus may encode information that may not be necessary for solution of the problem at hand (Gray, 1982), or animals with an intact hippocampus may solve the problem in a different way than animals without a hippocampus, even though both solutions are adequate (Eichenbaum et al., 1986). It is our hope that a thorough consideration of the behavioral correlates found here and in previous experiments will help to clarify and test some of these hypotheses. 

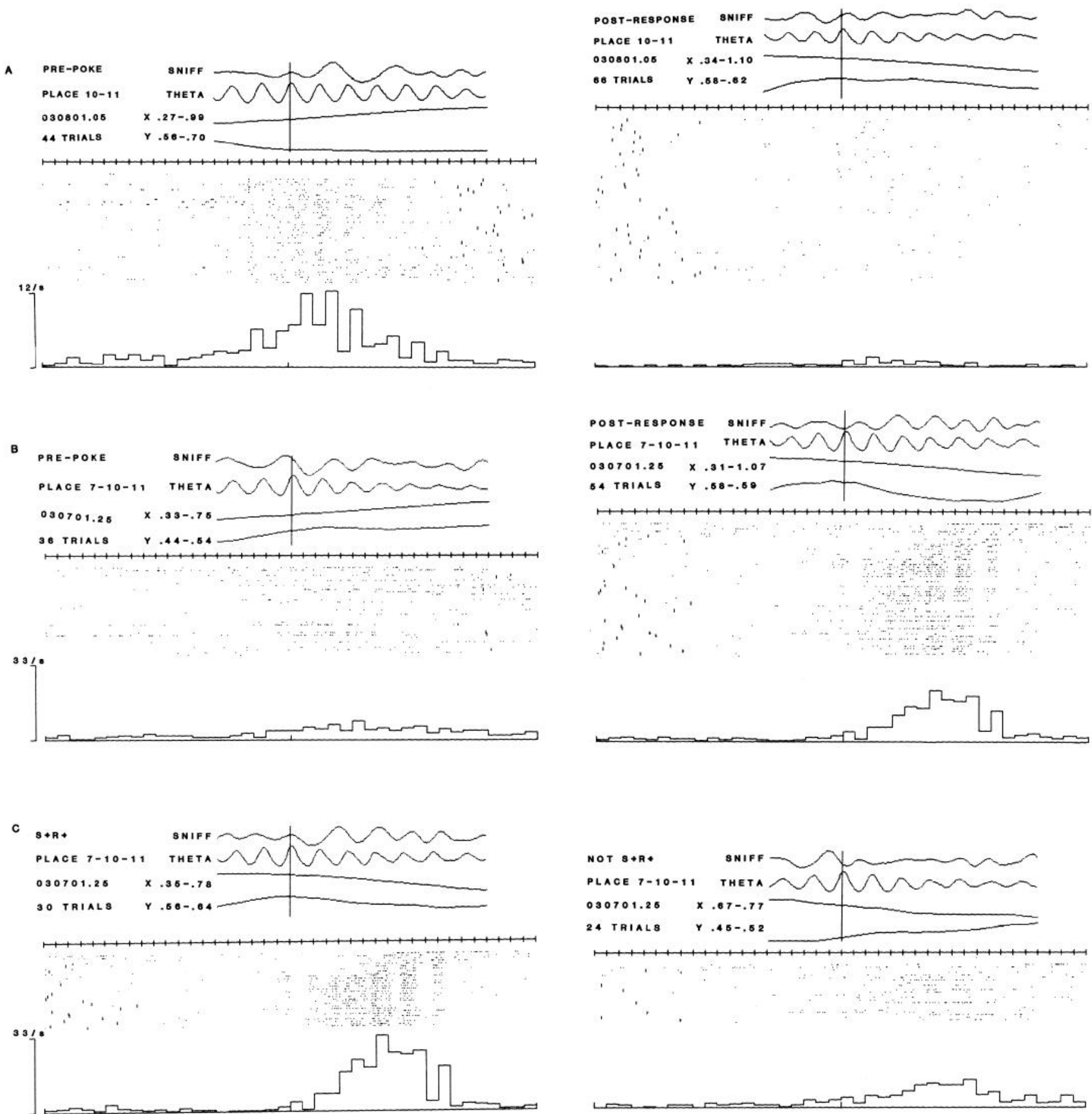

Figure 9. Detailed analyses of spatial firing in $(A)$ the port-approach cell shown in Figure $4 A$ and $(B$ and $C)$ the cup-approach cell shown in Figures $2 B$ and $5 C$. All measures are time-locked to the first negative peak of the theta rhythm after entry into the indicated place-field. $A$, Theta-phase related firing at the entry into the place-field in this port-approach cell is selective to the period before the nose poke (indicated by vertical bars in left panel) and not after onset of the nose poke (indicated by vertical bars in right panel). $B$, Theta-phase related firing at the entry into place-field in this cup-approach cell is selective to the period after offset of the nose poke (right) and not before onset of the nose poke (left). $C$, Place-field firing of the cell also shown in $B$ is considerably greater during trials in which reward is given (left) than when no reward is given (right).

In our interpretation of the behavioral correlates, we will first summarize the qualities of these cells and attempt to relate them to previously described behavioral correlates of hippocampal units. Then, we will speculate on possible relationships among the cell types and briefly discuss the implications of these findings for hypotheses about hippocampal function.
Cue-sampling cells and the analysis of conditioned stimuli by the hippocampus

Cue-sampling cells fire selectively during investigatory sniffing of task-related odor cues. These cells fire at relatively low average rates, and most were observed to fire with an occasional 

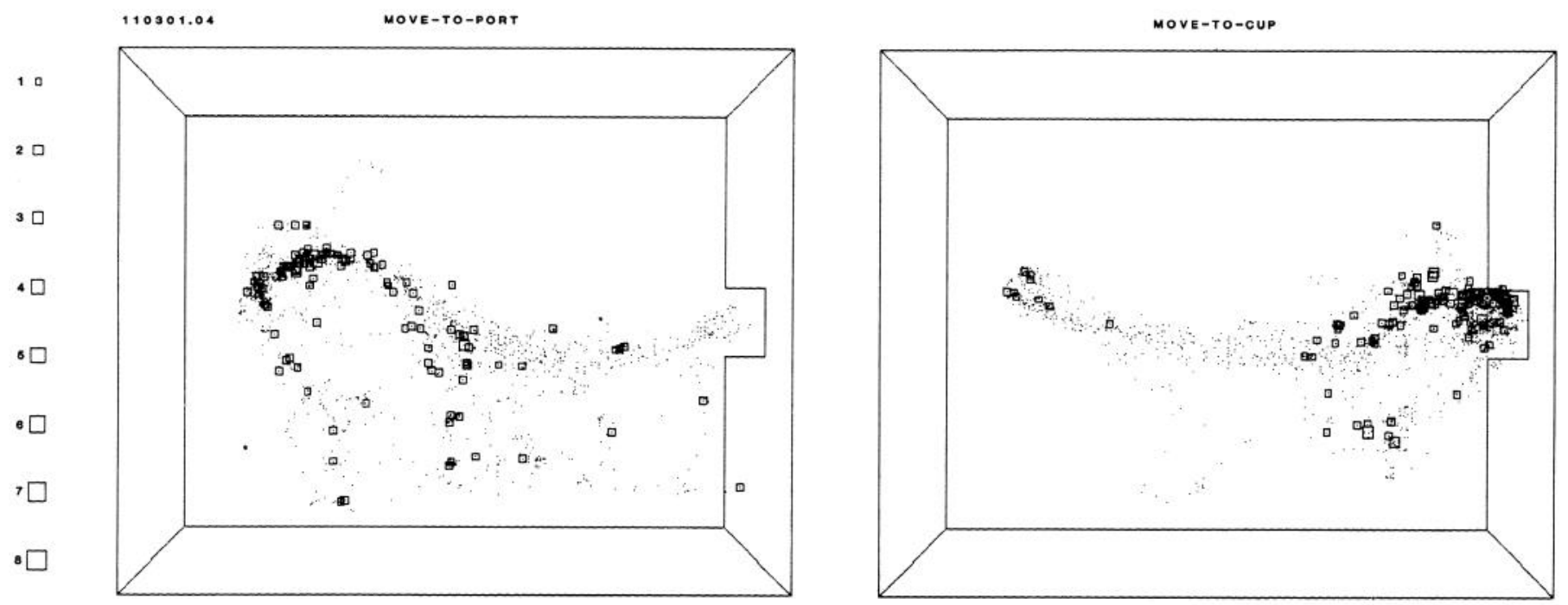

Figure 10. Path-maps of animal movements and unit activity for a cell active at the onset of both port (left) and cup (right) approach. Note considerable overlap of the 2 movement paths, but noncontiguous areas of firing, each selective to 1 behavioral period. Each panel includes 47 trials.

complex spike. Finally, they represent a relatively small proportion of the complex spike cell population observed. This combination of qualities suggests that these cells correspond to those Ranck (1973) described as "approach-consummate-mismatch" cells and those O'Keefe (1976) referred to as "misplace" cells. Both investigators described this cell type as firing maximally during exploratory sniffing, usually induced by removal of an expected stimulus or goal object in their paradigms. The firing correlate in their paradigms may not have been necessarily linked to the "mismatch" quality. It refers to the procedure used by these investigators to elicit exploratory sniffing. Both investigators note that firing is selective to a specific object or place for some of these cells. O'Keefe reported that some units fired selectively when the rat sniffed at a particular object in a particular place. Sampling cells reported here fire only in relation to odor cue sampling and do not fire during exploratory sniffing associated with approach to the reward cup. Thus, while unit activity increases are time-locked to inhalations, sniffing is not sufficient to drive the unit. Rather, a particular stimulus or kind of stimulus is required to elicit the firing increase. That these cells are relatively rare, as also observed by Ranck and O'Keefe, suggests that the appropriate stimulus for each cell may be rather specific and therefore seldom discovered within any particular experimental paradigm.

The synchronization of inhalation cycle, theta activity, and unit firing suggests that the hippocampus is engaged either in sensory processing or motor aspects of cue acquisition. The timing of these physiological events favors the sensory processing hypothesis: the synchronized theta rhythm and unit response follow the initiation of an investigatory sniff bout. However, different findings by other investigators may be used to support either the notion that the hippocampus is processing cues or guiding behavioral responses. Previous studies using tone-cued discrimination tasks have found that responses of complex spike cells are synchronized to conditioned stimuli and did not uncover a direct relation of unit firing to learned responses (Segal and Olds, 1973; Deadwyler et al., 1979). On the other hand, Berger and colleagues (1983), using a tone-cued classically conditioned discrimination, found that units were better time-locked to the conditioned response than to stimulus onset. In the present paradigm, the conditioned response did not require the initiation of new motor activity, only the maintenance of the nose position already in the port. Cue-sampling cells fire at long latency after nose-poke onset, so it is impossible to determine whether their activity is more associated with sensory-motor aspects of cue acquisition or the active continuation of the nose-poke response. Also, since our well-trained animals made few errors during recording sessions, it was impossible to adequately dissociate trials by stimulus type versus response type, thus preventing analyses of unit firing related to these variables independently.

Perhaps the most striking quality of cue-sampling cells was the influence of current and previous stimulus significance. Unit responses differentially increased over trials for rewarded stimuli, and responses were greatest during sampling of a positive stimulus preceded by a negative stimulus. These qualities have been observed in other conditioning paradigms (Segal and Olds, 1973; Deadwyler et al., 1979; Hampson et al., 1985). They appear to reflect a mechanism for recognizing stimuli in relation to others in their category, rather than in terms of their individual significance. This interpretation is consistent with converging evidence from clinical studies of human amnesia and experimental animal models of amnesia from which has emerged the view that the hippocampus is critically involved in learning relationships among stimulus elements of complex cues, between stimuli and associated responses, and between multiple stimuli presented successively in different time-frames (Hirsh, 1974; Olton et al., 1979; Cohen, 1984; Mishkin and Petri, 1984; Rawlins, 1985). Hippocampal system lesions impair the learning of conditional, contextual, or spatial stimulus associations (Hirsh, 1980; Winocur et al., 1980; Morris et al., 1982). In each of these studies, the critical cues are relational, in that reinforcement is accurately predicted only by the configuration of multiple independent stimuli. Parallel electrophysiological evidence of relational properties of hippocampal neurons has been found in monkeys, with cells that fire maximally to a particular visual pattern in a particular place (Rolls, 1985), and in rats, with cells that fire maximally when the animal is in a goal box of a par- 


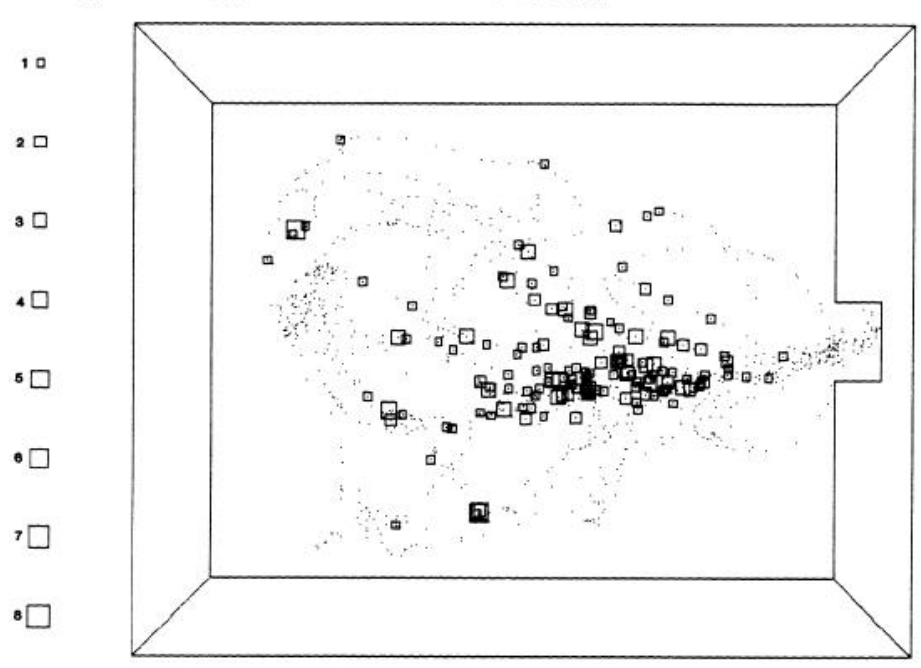

B

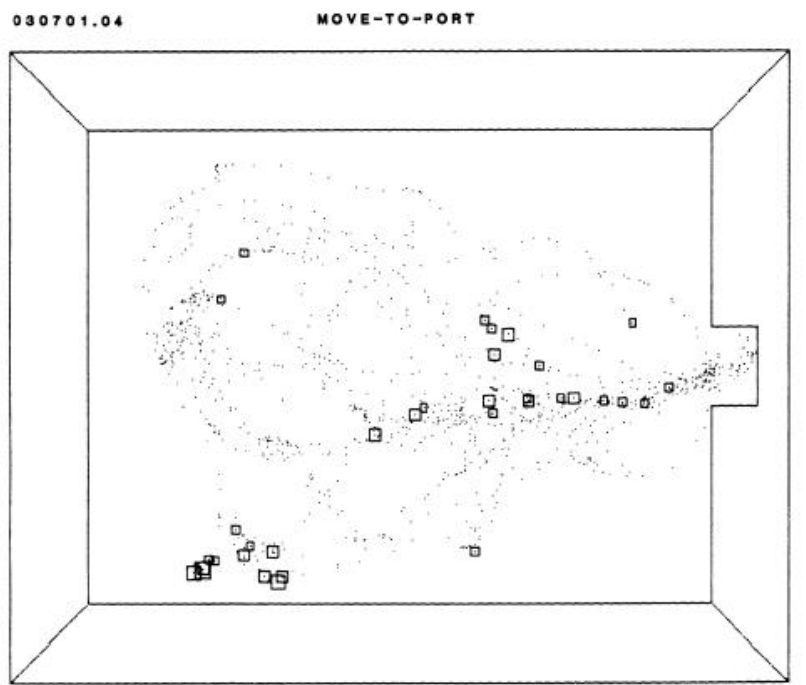

MOVE-TO-CUP

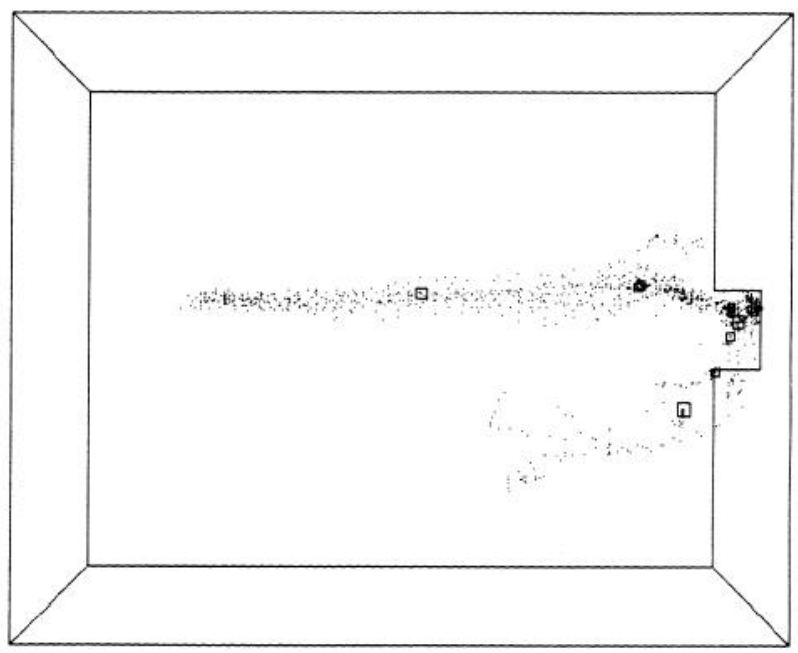

MOVE-TO-CUP

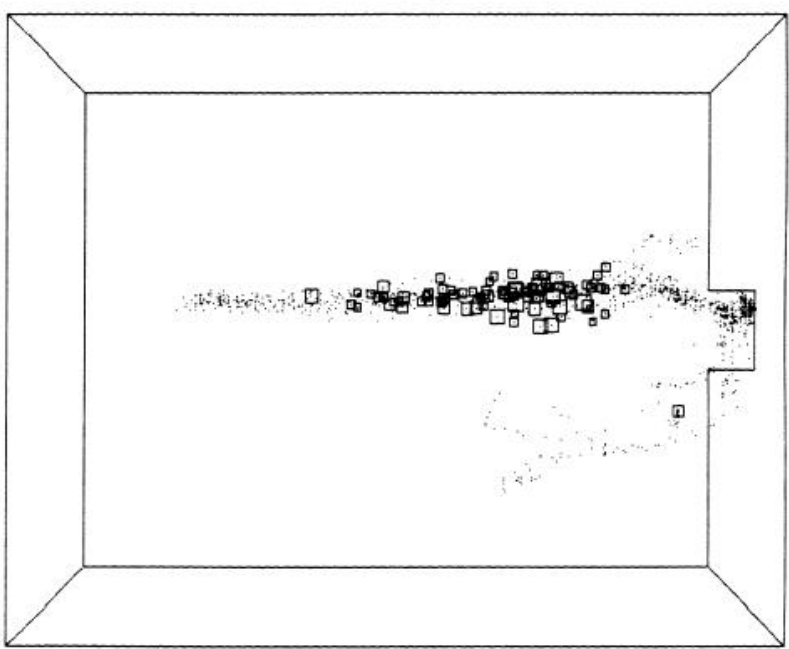

Figure 11. Path-maps of animal movements and unit firing locations for 2 cells with complementary behavioral correlates recorded simultaneously during the same 31 port- and 31 cup-approach periods. $A$, This port-approach cell fires at various locations during the movement towards the port (left) but not in overlapping areas during movement towards the reward cup (right). $B$, This cup-approach cell fires very little during movements towards the port (left) but considerably more in the same region of the path to the cup.

ticular color in a particular place (Wible et al., 1984). Similarly, there is evidence that damage to the hippocampal system impairs the learning of particular stimulus-response relationships (Gaffan, 1985). Again, there is parallel electrophysiological evidence for hippocampal units that fire for specific stimulus and response combinations (Rolls et al., 1985; Watanabe and Niki, 1985). The present data suggest that the hippocampus may also be critical to a representation of the relative significance of stimuli presented successively across time-frames. This could serve to bridge temporal or attentional gaps explicit in many memory paradigms (Eichenbaum et al., 1985; Rawlins, 1985) and implicit in successive discrimination tasks such as the one used here (Eichenbaum et al., 1986).

\section{Goal-approach cells and orientation towards objects of attention}

Goal-approach units fire selectively during specific orientation or locomotor movements, such as approach to the port or to the reward cup. These cells represent more than half of the cells recorded, fire at slow spontaneous rates, often with complex spikes, and are located mainly in the pyramidal cell layers of the hippocampus. These qualities are similar to those ascribed by Ranck (1973) to "approach-consummate" and "appetitive" cells. As in Ranck's study, some units fired only during approach to one goal, but most were not exclusive. Most of these units appeared to fire in 3-5 theta-related bursts at some transition of movement, i.e., at the initiation or cessation of movement. The finding that individual cells fire at select transitions of a goal-directed movement is quite similar to findings of Berger and colleagues (1983) showing that pyramidal cells in the rabbit fire at specific "phases" of conditioned eyeblinks.

Many of these units also had place-fields, defined as a firing preference for a particular area of the arena, regardless of ongoing behavior. Indeed, we believe this category of cells corresponds to those classified as "place cells" by O'Keefe and others (see O'Keefe, 1979). However, several aspects of the present results indicate that the activity of goal-approach cells does not simply reflect current animal location. Two lines of evidence argue against a straightforward spatial mapping function in the hippocampus: First, the place-field distribution was 

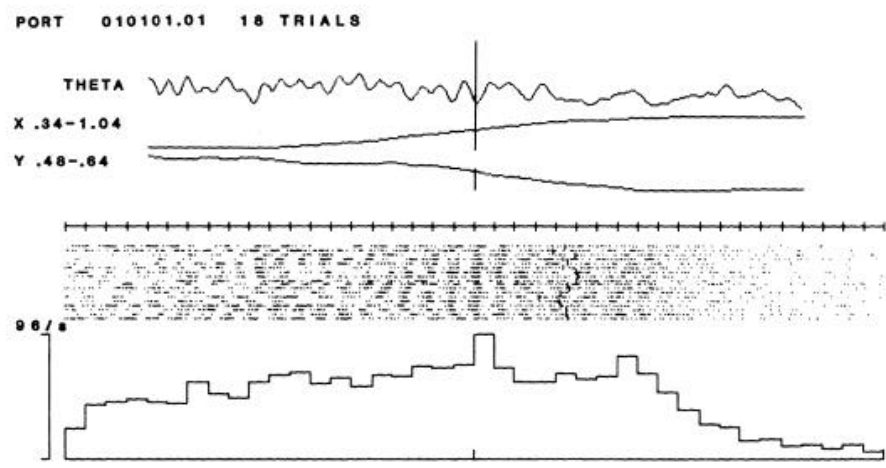
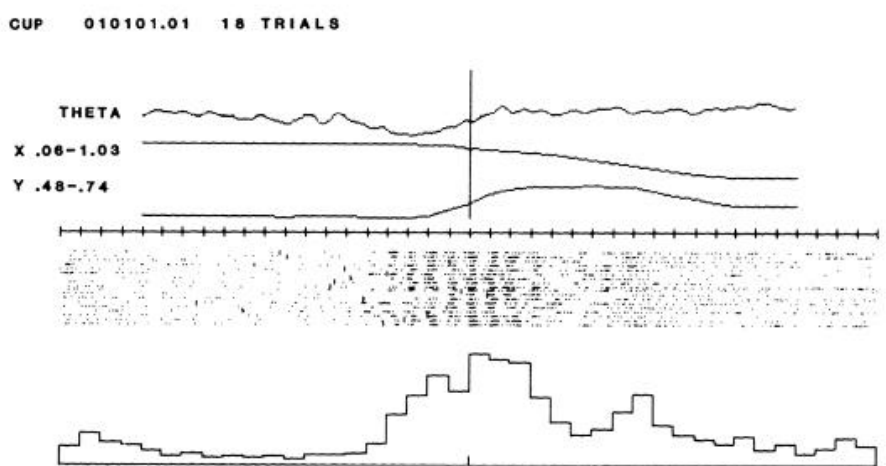

Figure 12. Detailed analysis of the theta cell shown in Figure $2 C$. Activity is time-locked to a positive peak of the theta rhythm during the period of maximal firing. The theta rhythm is suppressed in the panel at the right due to a recording artifact at the onset of movement. Left, Bursting repertoire of firing is maximal before onset of the nose poke (indicated by vertical bars in raster lines) but continues into the initial part of the sampling period. Right, Firing resumes maximal rate with movements away from the port and towards the cup after offset of the nose poke (indicated by vertical bars in raster lines).

far from homogeneous in those parts of the arena that were well sampled (Fig. 7), as would have been predicted by place-map theory (O'Keefe, 1979); most cells fired at the location where approach movements were initiated, nearby the odor port. Second, place-fields were seldom located in the port or at the cup. Yet, the firing of goal-approach cells is time-locked to arrival at one or both of these significant locations. For example, firing of the cup-approach cell described above was place-related (Figs. $8 B, 9 B$ ) but also synchronized to arrival at the cup location (Fig. 2B). Thus, unit activity in these cells is usually better correlated with a location-to-be-occupied (as much as $2 \mathrm{sec}$ in advance) than with the current location. To maintain the view that the hippocampus provides a map of space, one would have to account for a rather complicated map, including both current and subsequent locations.

Two other lines of evidence indicate that "spatial" firing is quite strongly modulated by ongoing behavior. First, time-locking to onset of movement often revealed better synchronization of unit activity than arrival in the place-field. There were many cells with an approach correlate and no well-defined place-field but only 1 cell with a place-field and no approach correlate. Second, the circumstances of entry into the place-field strongly modulated place firing. For example, the port-approach cell shown in Figure $4 A$ had a clear place-field (Fig. $9 A$ ) only during the port-approach period, even though the rat passed through the same place during the approach to the reward cup. Similarly, the cup-approach cell shown in Figure $5 C$ had a clear placefield only during the cup-approach period, and not during the port-approach period (Fig. 9B). In addition, cup-approach cells fired most vigorously only when the rat approached the cup for reward consumption, and not upon place-field entry on nonreinforced trials (Fig. 9C). Other approach cells fired synchronized to different approach movements in distinct locations (Fig. 10). Others fired exclusively during one approach behavior, even though the locations traversed during different behaviors overlapped considerably (Fig. 11).

Previous studies have varied widely in both the degree to which behavior was spatially structured and in the resulting observation of spatial versus behavioral correlates of unit activity. At one extreme of spatial testing, some have explicitly attempted to make behavior homogeneous throughout a large environment (e.g., Muller et al., 1983). There have been several paradigms with intermediate levels of behavioral structure in space. Maze tasks structure the behavioral repertoire along the length of the choice arms (although behavior has not always been explicitly taken into consideration in these paradigms), and they assume homogeneity of behavioral patterns across maze arms (Hill, 1978; Olton et al., 1978; McNaughton et al., 1983; Wible et al., 1984). Ranck's original observational chamber (1974), like our training paradigm, encouraged rats to move with specific purposes towards particular objects, each associated with a unique location. Finally, at the opposite extreme of spatial control, the eyelid conditioning paradigm involves restraint of the animal to a single place (Berger et al., 1983). Despite the wide range of variation in spatial and behavioral control, all groups have found striking correlates of unit activity.

Even in those paradigms aimed at analyses of spatial properties, investigators have noted that place firing is often conditional upon behavioral circumstances. For example, O'Keefe (1976) described place cells that "fired best when the rat ran past a part of the maze" (p. 105), rather than when it was still within the place-field. Kubie and colleagues (1984) also reported that place-cells had greater in-field to out-of-field firing ratios when rats were moving rather than stationary. Several reports showed that many place units were highly "directional," in that the cells fired only while the animal passed through the placefield in one direction (O'Keefe, 1976; Hill, reported in O'Keefe, 1979; McNaughton et al., 1983). As in the present experiment, these movements were always either towards or away from a specific goal. Combined with the present findings, these results clearly indicate that behavioral factors can be at least as powerful as spatial location in descriptions of hippocampal cell correlates. Whether paradigmatic constraints actually influence the degree to which unit activity is influenced by behavior versus location is unclear. We suggest that highly structured behavioral tasks, such as the present one, are particularly sensitive to the behavioral factors contributing to the firing of these cells. Conversely, behaviorally unstructured open-field environments will show an average of firing during many different behaviors, leaving spatial location as the only tested parameter. Only with a continued focus and greater refinement of behavior monitoring can we hope to sort out the spatial and behavioral aspects of the correlates of activity in these cells.

Our results indicate that approach cells fire during orientation movements with respect to specific targets of attention, i.e., goals. For many cells, increased firing was associated with the initial port approach performed at a variety of places (Fig. 11 $\mathrm{A}$ ), indicating that the orientation correlate of unit firing is related 
to the absolute (allocentric) location of the target, rather than the location of the target relative (egocentrically) to the position of the animal. With respect to their allocentric quality, our description of goal-approach cells and the absolute place quality attributed to these cells by O'Keefe and Nadel (1974) are compatible. The firing of cells associated with different paths of approach to the port (Fig. 11A) also suggests that it is more likely that unit activity is tied to the goal of the movement rather than to the specific movement pattern executed. Within the present task, the best description of goal-approach cells is that they fire during an act of orientation toward a target of attention, regardless of its immediate egocentric perspective or the movements required to obtain it.

\section{Theta cells and the significance of the theta rhythm}

The third major category of cells recorded comprised theta cells. These cells fired an order of magnitude faster than the other cell types and typically burst in synchrony with the ongoing theta rhythm. Theta cells can easily be distinguished from goal-approach cells since they increased firing during all approach behaviors and decreased firing during both of the relatively stationary behaviors (odor sampling and reward consumption) in the experimental paradigm. While EEG frequency and theta cell firing rate decreased during odor sampling, theta activity continued and was synchronized to the sniff bout. Thus, theta cells may be involved in both cue analysis and orientation and approach movements. The synchronization of sniffing, the theta rhythm, and complex spike cell activity suggests an entrainment of hippocampal processing cycles to sensorimotor activity, potentially governed by theta cells.

\section{Towards a framework for the functional circuit of the hippocampus}

Do the cue-sampling and goal-approach cells represent different sensitivities within the same functional population or functionally distinct cell populations? On the one hand, the combination of the cue-sampling cell and goal-approach cell groups yields a unit population with firing correlates spanning the series of trial events from port-approach to cup-arrival (Fig. 6). Individual neurons in this combined group could have fundamentally similar representations for specific salient events that occur during each period of the trial. Our data on sampling cells suggest that they are involved in comparisons of past and present sensory information. Could the goal-approach cells be involved in analogous comparisons during other trial periods? Goal-approach cells fire during specific learned movements, and their firing predicts arrival at a goal (the port or the cup). Voluntary movement correlates have been reported previously for hippocampal pyramidal cells (Ranck, 1973; Berger et al., 1983), dentate cells (Rose, 1983), and the hippocampal theta rhythm (Vanderwolf, 1971). Consistent with these electrophysiological findings, Gaffan and colleagues (1984) described deficits in memory for instrumental responses following fornix lesions. Perhaps both types of complex spike cells described here fire in relation to learned movements associated with different task requirements. Goalapproach cells may fire during voluntary movements associated with orientation toward goals of learned significance. Cue-sampling cells may fire in relation to head movements and sniffing associated with cue acquisition.

On the other hand, our categorization of cell types may have revealed properties of functionally separate and complementary populations of hippocampal cells. Previous descriptions have suggested complementary functional categories of complex spike cell types in the hippocampus. Ranck (1973) contrasted "approach-consummate" and "mismatch" cells, and O'Keefe (1976) described "place" and "misplace" cells. Our own scheme of sampling versus approach cells suggests one type of cell active during stimulus processing and the other active during orientation between sampling periods. The variations in these complementarities may merely reflect different emphases in individual experimental paradigms used to generate them.

Complementary organization of cell types is common in other brain systems. For example, within the peripontine reticular formation of the brain stem, distinct cell populations are related to alternating stages of visual fixation and orientation (Keller, 1974). "Pauser" cells fire tonically during fixation and stop firing during saccadic eye movements. In contrast, "burster" cells fire during saccades but not during fixation. While these complementary cell types are concerned with motor control, cue-sampling cells and goal-approach cells in the hippocampus might serve complementary roles in cognitive processing. Goal-approach cells might serve in specific stages of orientation between successive attentive fixations. During olfactory "fixations," characterized in the present study by synchronized sniffing and theta rhythm, cue-sampling cells might perform stimulus comparisons essential to construction of a relational representation of different odor values. Theta cells might be pacing the sequence of contiguous orientation movements and/or aligning sensory input during fixation.

These aspects of our model of hippocampal circuitry in rats may have analogs in humans that are relevant to the memory disorder seen after hippocampal damage. In rats, orientation may typically involve head or body movements towards the target of attention (see Goodale, 1983). In humans, the equivalent of goal-approach cells may serve in the orientation of attention without movement. The human counterpart of cuesampling cells could serve during attentive fixations in comparisons of present stimuli with representations of old ones in the construction of our system of relational representations. These speculations may be put in terms of the relationship between the hippocampus and its neocortical associations. The "orientation" correlated firing may reflect the search for a previously stored neocortical representation of a significant event, while the "sampling" correlate may reflect the matching of new episodic information with the retrieved neocortical image. These mechanisms may serve in processes by which the hippocampus contributes to the consolidation of declarative memories in neocortex (Squire et al., 1984).

This speculative account of complementarity in hippocampal circuitry offers a mechanistic organization of hippocampal function that incorporates each cell type observed here. Further use of structured learning environments with creative manipulations of task variables may provide empirical dissociation of our hypotheses regarding single versus complementary cell populations in the hippocampus. This endeavor would particularly benefit by an understanding of the interactive properties of these cell types to reveal their cooperative activity and topographical relationships (Eichenbaum and Kuperstein, 1986; Kuperstein et al., 1986).

\section{References}

Berger, T. W., P. C. Rinaldi, D. J. Weisz, and R. F. Thompson (1983) Single-unit analysis of different hippocampal cell types during classical conditioning of the nictitating membrane response. J. Neurophysiol. 50: 1197-1219. 
Best, P. J., and J. B. Ranck (1982) The reliability of the relationship between hippocampal unit activity and sensory-behavioral events in the rat. Exp. Neurol. 75: 652-664.

Best, P. J., and L. T. Thompson (1984) Hippocampal cells which have place field activity also show changes in activity during classical conditioning. Soc. Neurosci. Abstr. 10: 125.

Christian, E. P., and S. A. Deadwyler (1986) Behavioral functions and hippocampal cell types: Evidence for two nonoverlapping populations in the rat. J. Neurophysiol. 55: 331-348.

Cohen, N. J. (1984) Preserved learning capacity in amnesia: Evidence for multiple memory systems. In The Neuropsychology of Memory, N. Butters and L. R. Squire, eds., pp. 83-103, Guilford, New York.

Deadwyler, S. A., M. West, and G. Lynch (1979) Activity of dentate granule cells during learning: Differentiation of perforant path input. Brain Res. 169: 29-43.

Eichenbaum, H., and M. Kuperstein (1986) Extracellular neural recording with multichannel microelectrodes. J. Electrophysiol. Tech. 13: 189-209.

Eichenbaum, H., D. Pettijohn, A. M. Deluca, and S. L. Chorover (1977) Compact miniature microelectrode-telemetry system. Physiol. Behav. 18: $1175-1178$

Eichenbaum, H., T. Parikh, and N. Cohen (1985) Delayed non-match to sample with trial unique odor stimuli in intact and fornix-damaged rats: A new test for recognition memory and model of temporal lobe amnesia. Soc. Neurosci. Abstr. 11: 333.

Eichenbaum, H., A. Fagan, and N. Cohen (1986) Normal olfactory discrimination learning set and facilitation of reversal learning after medial-temporal damage in rats: Implications for an account of preserved learning abilities in amnesia. J. Neurosci. 6: 1876-1884.

Fox, S. E., and J. B. Ranck (1975) Localization and anatomical identification of theta and complex spike cells in dorsal hippocampus in rats. Exp. Neurol. 49: 299-313.

Fox, S. E., and J. B. Ranck (1981) Electrophysiological characteristics of hippocampal complex-spike cells and theta cells. Exp. Brain Res. 41: 399-410.

Gaffan, D. (1985) Hippocampus: Memory, habit and voluntary movement. Phil. Trans. R. Soc. Lond. [Biol.] 308: 87-99.

Gaffan, D., C. Shields, and S. Harrison (1984) Delayed matching by fornix-transected monkeys: The sample, the push and the bait. Q. J. Exp. Psychol. 36B: 305-317.

Goodale, M. A. (1983) Neural mechanisms of visual orientation in rodents: Targets versus places. In Spatially Oriented Behavior, A. Hein and M. Jeannerod, eds., pp. 35-61, Springer-Verlag, New York.

Gray, J. A. (1982) The Neuropsychology of Anxiety: An Enquiry into the Functions of the Septo-Hippocampal System, Oxford U. P., Oxford.

Hampson, R. E., T. C. Foster, E. P. Christian, K. A. Campbell, and S. A. Deadwyler (1985) Sequential dependencies regulate sensory evoked response of single units in the rat hippocampus. Soc. Neurosci. Abstr. 11: 526.

Hill, A. J. (1978) First occurrence of spatial firing in a new environment. Exp. Neurol. 62: 282-297.

Hirsh, R. (1974) The hippocampus and contextual retrieval of information from memory: A theory. Behav. Biol. 12: 421-444.

Hirsh, R. (1980) The hippocampus, conditional operations and cognition. Physiol. Psychol. 8: 175-182.

Jones-Leonard, B., B. L. McNaughton, and C. A. Barnes (1985) Longterm studies of place field interrelationships in dentate gyrus neurons. Soc. Neurosci. Abstr. 11: 1108.

Keller, E. L. (1974) Participation of the medial pontine reticular formation in eye movement generation in monkey. J. Neurophysiol. 37 : 316-332.

Kubie, J. L. (1984) A driveable bundle of microwires for collecting single-unit data from freely moving rats. Physiol. Behav. 32: 115118 .

Kubie, J. L., and J. B. Ranck (1983) Sensory-behavioral correlates in individual hippocampus neurons in three situations: Space and context. In Neurobiology of the Hippocampus, W. Seifert, ed., pp. 433447, Academic, New York.

Kubie, J. L., S. E. Fox, and R. U. Muller (1984) Variations in place cell firing with the state of the hippocampal EEG. Soc. Neurosci. Abstr. 10: 599.

Kuperstein, M., H. Eichenbaum, and T. VanDeMark (1986) Neural group properties in the rat hippocampus during the theta rhythm. Exp. Brain Res. 61: 438-442.
Macrides, F., H. Eichenbaum, and W. Forbes (1982) Temporal relationship between sniffing and the limbic theta rhythm during odor discrimination reversal learning. J. Neurosci. 2: 1705-1717.

McNaughton, B. L., C. A. Barnes, and J. A. O'Keefe (1983) The contributions of position, direction, and velocity to single cell unit activity in the hippocampus of freely moving rats. Exp. Brain Res. 52: $41-49$.

Mishkin, M., and H. L. Petri (1984) Memories and habits: Some implications for the analysis of learning and retention. In The Neuropsychology of Memory, N. Butters and L. R. Squire, eds., pp. 287296, Guilford, New York.

Morris, R. G. M., P. Garrud, J. N. P. Rawlins, and J. O'Keefe (1982) Place navigation impaired in rats with hippocampal lesions. Nature 297: 681-683.

Muller, R. U., and J. L. Kubie (1984) Spatial firing of hippocampal cells: Putting barriers in the environment. Soc. Neurosci. Abstr. 10: 124.

Muller, R. U., J. L. Kubie, and J. B. Ranck (1983) High resolution mapping of the "spatial" fields of hippocampal neurons in the freely moving rat. Soc. Neurosci. Abstr. 9: 646.

O'Keefe, J. A. (1976) Place units in the hippocampus of the freely moving rat. Exp. Neurol. 51: 78-109.

O'Keefe, J. A. (1979) A review of hippocampal place cells. Prog. Neurobiol. 13: 419-439.

O'Keefe, J. A. (1983) Spatial memory within and without the hippocampal system. In Neurobiology of the Hippocampus, W. Seifert, ed., pp. 375-403, Academic, London.

O'Keefe, J. A., and D. H. Conway (1980) On the trail of the hippocampal engram. Physiol. Psychol. 2: 229-238.

O'Keefe, J. A., and L. Nadel (1978) The Hippocampus as a Cognitive Map, Oxford U. P., Oxford.

Olton, D., M. Branch, and P. J. Best (1978) Spatial correlates of hippocampal unit activity. Exp. Neurol. 58: 387-409.

Olton, D., J. T. Becker, and G. E. Handlemann (1979) Hippocampus, space, and memory. Brain Behav. Sci. 2: 313-365.

Ranck, J. B. (1973) Studies on single neurons in the hippocampal formation and septum in unrestrained rats. Part I. Behavioral correlates and firing repertoires. Exp. Neurol. 40: 461-531.

Rawlins, J. N. P. (1985) Associations across time: The hippocampus as a temporary memory store. Behav. Brain Sci. 8: 479-496.

Rolls, E. T., Y. Miyashita, P. Cahusac, and R. P. Kesner (1985) The responses of single neurons in the primate hippocampus related to performance in memory tasks. Soc. Ncurosci. Abstr. 11: 525.

Rose, G. (1983) Physiological and behavioral characteristics of dentate granule cells. In Neurobiology of the Hippocampus, W. Seifert, ed., pp. 449-472, Academic, New York.

Segal, M., and J. Olds (1972) The behavior of units in the hippocampal circuit during learning. J. Neurophysiol. 35: 680-690.

Segal, M., and J. Olds (1973) Activity of units in the hippocampal circuit of the rat during differential classical conditioning. J. Comp. Physiol. Psychol. 82: 195-204.

Segal, M., J. Disterhoft, and J. Olds (1972) Hippocampal unit activity during aversive and appetitive conditioning. Science 175: 792-794.

Squire, L., N. J. Cohen, and L. Nadel (1984) The medial temporal region and memory consolidation: A new hypothesis. In Memory Consolidation: Psychobiology of Cognition, $\mathrm{H}$. Weingartner and $\mathrm{E}$. Parker, eds., pp. 185-210, L. Erlbaum, Hillsdale, NJ.

Thompson, R. F., T. W. Berger, S. D. Berry, F. K. Hoeler, R. E. Kettner, and D. J. Weisz (1980) Hippocampal substrate of classical conditioning. Physiol. Psychol. 8: 262-279.

Vanderwolf, C. H. (1971) Limbic-diencephalic mechanisms of voluntary movement. Psychol. Rev. 78: 83-113.

Watanabe, T., and H. Niki (1985) Hippocampal unit activity and delayed response in the monkey. Brain Res. 325: 241-254.

West, M. O., E. Christian, J. H. Robinson, and S. A. Deadwyler (1981) Dentate granule cell discharge during conditioning. Exp. Brain Res. 44: $287-294$

Wible, C. G., E. J. Lang, and D. S. Olton (1984) Single unit activity in the hippocampus: Behavioral correlates in nonspatial and spatial reference memory tasks. Soc. Neurosci. Abstr. 10: 124.

Winocur, G. (1980) The hippocampus and cue utilization. Physiol. Psychol. 8: 280-288.

Winson, J. (1974) Patterns of hippocampal theta rhythm in the freelymoving rat. Electroencephalogr. Clin. Neurophysiol. 36: 291-301. 